Article

\title{
Removal of Chromium(VI) by Chitosan Beads Modified with Sodium Dodecyl Sulfate (SDS)
}

\author{
Xiaoyu Du ${ }^{1}$, Chihiro Kishima ${ }^{1}$, Haixin Zhang ${ }^{1}$, Naoto Miyamoto ${ }^{2}$ and Naoki Kano ${ }^{2, *(D)}$ \\ 1 Graduate School of Science and Technology, Niigata University, 8050 Ikarashi 2-Nocho, Nishi-ku, \\ Niigata 950-2181, Japan; F17K502A@mail.cc.niigata-u.ac.jp (X.D.); c_kishima@nokkluber.co.jp (C.K.); \\ F19B137H@mail.cc.niigata-u.ac.jp (H.Z.) \\ 2 Department of Chemistry and Chemical Engineering, Faculty of Engineering, Niigata University, \\ 8050 Ikarashi 2-Nocho, Nishi-ku, Niigata city, Niigata 950-2181, Japan; nmiyamoto@eng.niigata-u.ac.jp \\ * Correspondence: kano@eng.niigata-u.ac.jp; Tel.: +81-025-262-7218
}

Received: 5 June 2020; Accepted: 8 July 2020; Published: 9 July 2020

\begin{abstract}
In this study, chitosan beads modified with sodium dodecyl sulfate (SDS) were successfully synthesized and employed for the removal of chromium(VI) $(\mathrm{Cr}(\mathrm{VI}))$. The adsorption performance of the adsorbent (SDS-chitosan beads) was examined by batch experiments. The partition coefficient (PC) as well as the adsorption capacity were evaluated to assess the true performance of the adsorbent in this work. The adsorbent (SDS-chitosan beads) showed a maximum $\mathrm{Cr}(\mathrm{VI})$ adsorption capacity of $3.23 \mathrm{mg} \cdot \mathrm{g}^{-1}$ and PC of $9.5 \mathrm{mg} \cdot \mathrm{g}^{-1} \cdot \mathrm{mM}^{-1}$ for $\mathrm{Cr}(\mathrm{VI})$. The prepared adsorbent was characterized by different techniques such as scanning electron microscopy-energy dispersive $\mathrm{X}$-ray spectroscopy (SEM-EDS), X-ray photoelectron spectroscopy (XPS) and Fourier transform-infrared spectroscopy (FT-IR). We used inductively coupled plasma mass spectrometry (ICP-MS) for the determination of $\mathrm{Cr}(\mathrm{VI})$ in solution. The experimental data could be well-fitted by pseudo-second-order kinetic and Langmuir isotherm models. The thermodynamic studies indicated that the adsorption process was favorable under the higher temperature condition. The SDS-modified chitosan beads synthesized in this work represent a promising adsorbent for removing $\mathrm{Cr}(\mathrm{VI})$.
\end{abstract}

Keywords: chitosan beads; sodium dodecyl sulfate (SDS); hexavalent chromium ions; adsorption capacity; partition coefficient

\section{Introduction}

Toxic metal contamination in aquatic environments has attracted tremendous attention due to the rapidly increasing number of manufacturing industries. Heavy metals are of major environmental concern because they are non-biodegradable and cannot be decomposed or metabolized [1]. Several metals cause serious health and environment problems, and chromium $(\mathrm{Cr})$ compounds are one of the most toxic contaminants in wastewater due to their high solubility and toxicity, and free transferability [2]. Cr has been widely applied in many industrial activities based on its excellent properties, for example, such as in electroplating, leather tanning, nuclear power plants, and textile industries [3,4]. Moreover, it can be used for anodizing, corrosion control, and chemical manufacturing [5-7]. Chromium usually exists in two stable oxidation states: trivalent $\mathrm{Cr}(\mathrm{III})$ and hexavalent $\mathrm{Cr}(\mathrm{VI})$ in a natural environment, as its other oxidation states are not stable in aerated aqueous media [8]. In a natural aqueous environment, $\mathrm{Cr}(\mathrm{VI})$ may exist in the form of $\mathrm{CrO}_{4}{ }^{2-}$ or $\mathrm{HCrO}_{4}{ }^{-}$, whereas $\mathrm{Cr}(\mathrm{III})$ is inclined to form $\left[\mathrm{Cr}\left(\mathrm{H}_{2} \mathrm{O}\right)_{6}\right]^{3+}, \mathrm{Cr}\left(\mathrm{H}_{2} \mathrm{O}\right)_{5}(\mathrm{OH})^{2+}, \mathrm{Cr}\left(\mathrm{H}_{2} \mathrm{O}\right)_{4}(\mathrm{OH})_{2}{ }^{+}$, or $\mathrm{Cr}(\mathrm{III})$ organic complexes. It is well-known that $\mathrm{Cr}(\mathrm{III})$ is an essential material for organisms, whereas $\mathrm{Cr}(\mathrm{VI})$ is more toxic, carcinogenic, and mutagenic [8,9]. Thus, the development of a recovery method for this metal (particularly $\mathrm{Cr}(\mathrm{VI})$ ) is significant from the standpoint of environmental protection. Many physical and 
chemical technologies, such as ion exchange, precipitation, ultrafiltration, reverse osmosis, and electro dialysis, have been reported and used for removing heavy metals [10]. Nevertheless, these procedures have some disadvantages, such as a high consumption of reagents and energy, low selectivity, high operational costs and difficult further treatment due to the generation of toxic sludge [11]. Adsorption is considered to be an efficient method for removing metallic ions in aqueous solutions [12,13]; in particular, biological adsorption (biosorption) is one of the most environmentally friendly, economically favorable, low cost, recyclable, and technically easy methods [14,15].

Among the many biosorbents available, chitosan can be an outstanding biosorbent for metals for the reason that its amine $\left(-\mathrm{NH}_{2}\right)$ and hydroxyl $(-\mathrm{OH})$ groups may serve as coordination sites to form complexes with various heavy metal ions [16]. Chitosan has been proven to be very efficient as a biosorbent for the recovery of several toxic metals such as mercury (Hg), uranium (U), molybdenum (Mo), vanadium (V), and platinum (Pt) [17-19], and its full chemical name is called $(1,4)-2$-amino-2-deoxy- $\beta$-D-glucose. It can be employed as an environmentally friendly adsorbent due to it being economical and the fact that it does not result in secondary pollution. Chitosan can be produced by the alkaline deacetylation of chitin, which originates from the most abundant biopolymer-cellulose. Chitosan is a polymer that can be acquired from the shells of seafood, such as prawns, crabs, and lobsters [20]. The biopolymer is characterized by a high percentage of nitrogen, and exists in the form of amine groups, free amino groups, and hydroxyl groups, which are responsible for metal ion binding through chelation mechanisms [21].

The uses of chitosan in the removal of various pollutants have been adequately reviewed [22]. However, chitosan has some defects, such as notable swelling in aqueous media and nonporous structures, resulting in a very low surface area [23]. Therefore, many types of chemical modification can be undertaken to produce chitosan derivatives for improving the removal efficiency of the heavy metal [24]. For example, various chemical or physical modifications can be adopted for increasing the number of exposed active sites $[25,26]$. Moreover, silicon dioxide can be employed to offset the defects of chitosan because it has many properties, such as a rigid configuration, porosity, and a high surface area. In the case of silicon dioxide, modified silicon dioxide produced through the graft between silanol groups and ligands has been developed [27-29]. We have synthesized a hybrid membrane of carboxymethyl chitosan and silicon dioxide as adsorbents for the removal of $\mathrm{Cr}(\mathrm{VI})$ in our previous work [30]. Furthermore, we have carried out an adsorption experiment of chromate ions onto cross-linked chitosan using epichlorohydrin (EP) and glutaraldehyde (GA) as cross-linked agents [31].

In this work, we evaluated the adsorption of chitosan modified with sodium dodecyl sulfate (SDS) as part of the adsorption study of $\mathrm{Cr}$ using modified chitosan. It has been reported that SDS-modified chitosan beads can be used to remove cationic dyes. [32]. The metal ion strength and the presence of key functional groups on the polymer chain allow its adsorption on surfaces [33-35]. The aggregation of particles through a bridging structure can be described as a two-step pathway: (1) initial chain adsorption and bridging, followed by (2) floc maturation/reconfiguration. Before the interparticle connection occurs, the chain of SDS must be adsorbed on a chitosan surface [36]. Furthermore, chitosan modified with SDS has recently been used for the removal of heavy metals, such as cadmium [37,38]. However, the use of SDS-modified chitosan as an adsorbent of $\mathrm{Cr}$, with varying initial concentrations of SDS for optimizing the adsorbent, has rarely been evaluated. The objective of the present research was to investigate the efficiency of SDS-modified chitosan beads as a sorbent for $\mathrm{Cr}(\mathrm{VI})$ for more practical uses in the future, and to reveal the adsorption mechanism. After the characterization of SDS-chitosan by scanning electron microscopy-energy dispersive X-ray spectroscopy (SEM-EDS), X-ray photoelectron spectroscopy (XPS) and Fourier transform-infrared spectroscopy (FT-IR), batch experiments using SDS-modified chitosan beads were conducted to optimize the parameters, in order to obtain the maximum removal of $\mathrm{Cr}(\mathrm{VI})$. The effects of various parameters, such as the solution $\mathrm{pH}$, contact time, adsorbent dose, and initial concentration, were examined. 


\section{Materials and Methods}

Chemical reagents, including chitosan and sodium dodecyl sulfate (SDS; M.W.: $288.372 \mathrm{~g} / \mathrm{mol}$ ), were purchased from Tokyo Chemical Industry Co., Inc. (Tokyo, Japan). Acetic acid, $\mathrm{NaOH}, \mathrm{HNO}_{3}$, $\mathrm{NaSO}_{4}$, ethylenediaminetetraacetic acid disodium salt dihydrate, and toluene were obtained from Kanto Chemical Industry Co., Inc. All reagents used were of analytical grade. During the whole working process, water $(>18.2 \mathrm{M} \Omega$ ) treated by the ultrapure water system (RFU 424TA, Advantech Aquarius) was employed. In order to prepare the $\mathrm{Cr}$ standard solution for the calibration curve, the standard solution (Kanto Chemical Co., Inc., $1000 \mathrm{mg} \cdot \mathrm{L}^{-1} \mathrm{~K}_{2} \mathrm{CrO}_{7}$ solution) was diluted and used.

\subsection{Synthesis of the Adsorbent}

Chitosan powder with a molecular weight (50-190 kDa) and degree of deacetylation $(>80 \%)$ was used in this work. The viscosity of chitosan is 20 to $100 \mathrm{mPa} \cdot \mathrm{s}$ (in $0.5 \%$ acetic acid, $20^{\circ} \mathrm{C}$; degree Celsius) after drying. At first, $1.5 \mathrm{~g}$ of chitosan was placed in acetic acid solution $(2.0 \%)$, and the solution was mixed for $24 \mathrm{~h}$. The chitosan gel was prepared by dropping the above chitosan solution into $200 \mathrm{~mL}$ of $0.20 \mathrm{~mol} \cdot \mathrm{L}^{-1} \mathrm{NaOH}$. The obtained gel was rinsed with ultrapure water until attaining a $\mathrm{pH}$ of 7 after stirring for $24 \mathrm{~h}$. Subsequently, 200 tablets of chitosan gel beads were placed in $100 \mathrm{~mL}$ SDS solution (including the fixed concentration of SDS), and then, left for five days. Therefore, chitosan gel beads modified with SDS were obtained. Finally, the SDS-modified chitosan beads were dried at $60^{\circ} \mathrm{C}$ overnight for their use as an adsorbent. The procedure employed for the synthesis of SDS-chitosan beads is shown in Figure 1. It is considered that the prepared adsorbent has a bilayer of SDS over the surface of pure chitosan beads. This bilayer can have a higher ion capturing capacity [37].

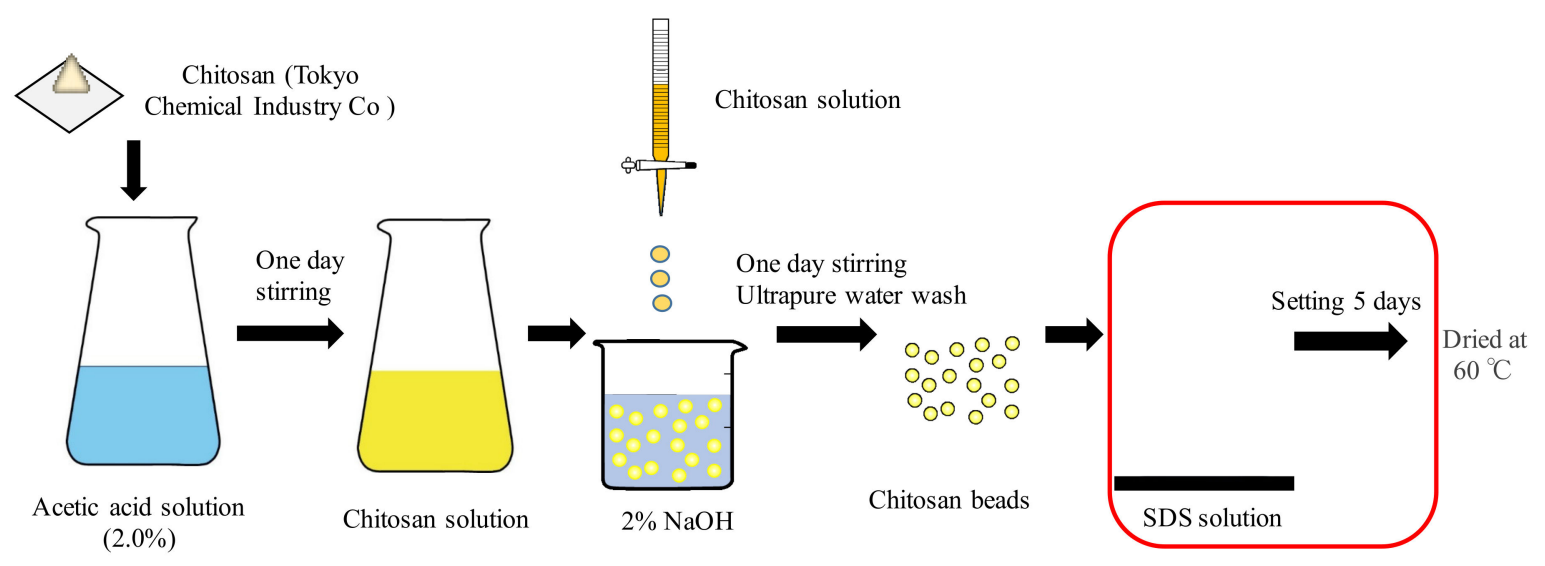

Figure 1. Procedure employed for the synthesis of sodium dodecyl sulfate (SDS)-chitosan beads.

\subsection{Characterization of the Adsorbent}

The diameter of chitosan beads was found to be about $0.5-2 \mathrm{~mm}$ (judging from 200 beads as representative chitosan beads). The data obtained after weighing 200 hydrogel beads showed that the dry weight per chitosan bead was $3.7 \times 10^{-4} \mathrm{~g}$, which suggests that the adsorbent contained $98 \%$ moisture. Several characterization methods have been used to determine the physicochemical properties of pristine and modified chitosan. FT-IR spectra of the samples were recorded in the range of 4000-500 $\mathrm{cm}^{-1}$ with a JASCO Japan FTIR-4200 spectrophotometer using the KBr pellet method. The surface morphology and element distribution of the chitosan beads before and after the adsorption of $\mathrm{Cr}(\mathrm{VI})$ were obtained using SEM-EDS (JEOL Japan: JCM-6000 with JED-2300). The surface chemistry properties of SDS-modified chitosan beads were investigated by X-ray Photoelectron Spectroscopy (XPS, Thermo Scientific Center: K-Alpha). 


\subsection{Adsorption Experiments}

The SDS-chitosan beads synthesized in Section 2.1. were employed as the adsorbent of $\mathrm{Cr}(\mathrm{VI})$ in this study. The beads were placed in a $200 \mathrm{~mL}$ conical flask containing $50 \mathrm{~mL}$ of aqueous solution with a known amount of $\mathrm{Cr}(\mathrm{VI})$, and the suspensions were placed in a constant temperature-shaker (TAITEC Plus Shaker $\mathrm{EP}^{-1}$ with Thermo Minder SX-10R) set at a prescribed temperature. Adsorption experiments were performed in the $\mathrm{pH}$ range of $1-7$, SDS initial concentration of $10-9000 \mathrm{mg} \cdot \mathrm{L}^{-1}$, contact time of 1 to $72 \mathrm{~h}$, adsorbent dosage of $0.01-0.06 \mathrm{~g} \cdot \mathrm{L}^{-3}$, temperature of $288-318 \mathrm{~K}$, and initial $\mathrm{Cr}(\mathrm{VI})$ concentration of $0.1-3.0 \mathrm{mg} \cdot \mathrm{L}^{-1}$. The $\mathrm{pH}$ of the test solution was adjusted by adding $0.1 \mathrm{~mol} \cdot \mathrm{L}^{-1}$ $\mathrm{NaOH}$ or $\mathrm{HNO}_{3}$. Secondary to the adsorption experiment, the suspension was filtered with $0.45 \mu \mathrm{m}$ filter paper (Mixed Cellulose Ester $47 \mathrm{~mm}$, Advantec MFS, Inc. (Tokyo, Japan)), and the concentration of $\mathrm{Cr}$ was determined by an ICP-MS (Thermo Scientific Center: X-series II). Replicate experiments were basically performed three times. The operating conditions of ICP-MS are shown in Table 1.

$$
q_{e}=\frac{\left(C_{i}-C_{e}\right)}{m} \cdot V
$$

where $q_{e}$ represents the adsorption capacities at equilibrium $\left(\mathrm{mg} \cdot \mathrm{g}^{-1}\right), C_{\mathrm{i}}$ and $C_{\mathrm{e}}$ are the initial and equilibrium concentrations of $\mathrm{Cr}$ in a batch system, respectively $\left(\mathrm{mg} \cdot \mathrm{L}^{-1}\right) ; V$ is the volume of the solution (L); $m$ is the weight of adsorbent (g).

Table 1. Operating conditions of inductively coupled plasma mass spectrometry (ICP-MS).

\begin{tabular}{cc}
\hline Parameter & Condition \\
\hline Plasma Conditions & \\
RF frequency & $27.1 \mathrm{MHz}$ \\
RF power & $1400 \mathrm{~W}$ \\
Gas conditions & $15 \mathrm{~L} \cdot \mathrm{min}^{-1}$ \\
Plasma gas flow & $1.2 \mathrm{~L} \cdot \mathrm{min}^{-1}$ \\
Carrier gas flow & $6.5 \mathrm{~mm}$ \\
Sample conditions & $0.5 \mathrm{~mL} \cdot \mathrm{min}^{-1}$ \\
Sampling depth & $3 \mathrm{points} /$ peak \\
Sample uptake rate & $1.0 \mathrm{sec} /$ point \\
Measurement point & $52 \mathrm{Cr}$ \\
Integration time & \\
Measured isotope &
\end{tabular}

\subsection{Adsorption Isotherm}

Adsorption isotherms are commonly used to reflect the performance of adsorbents in adsorption processes. To examine the relationship between the metal uptake $\left(q_{\mathrm{e}}\right)$ and the concentration of metal ions $\left(C_{\mathrm{e}}\right)$ at equilibrium, adsorption isotherm models are widely employed for fitting the data. To investigate the equilibrium data, initial concentrations of metals were varied while the adsorbent weight of each sample was kept constant. Langmuir and Freundlich isotherms models were applied to evaluate the adsorption data obtained in this study.

The Langmuir model assumes monolayer adsorption on a surface and is given by

$$
\frac{C_{e}}{q_{e}}=\frac{C_{e}}{q_{\max }}+\frac{1}{K_{L} q_{\max }}
$$

where $C_{\mathrm{e}}$ and $q_{\mathrm{e}}$ are the concentration of $\mathrm{Cr}$ at equilibrium $\left(\mathrm{mg} \cdot \mathrm{L}^{-1}\right)$ and the amount of adsorption of $\mathrm{Cr}(\mathrm{VI})$ at equilibrium $\left(\mathrm{mg}^{-1} \mathrm{~g}^{-1}\right)$, respectively; $q_{\max }$ is the maximum adsorption capacity on the surface of the chitosan bead $\left(\mathrm{mg}^{-1} \mathrm{~g}^{-1}\right) ; K_{L}$ is the equilibrium adsorption constant $\left(\mathrm{L} \cdot \mathrm{mg}^{-1}\right)$. A plot of $C_{e} / q_{e}$ versus $C_{e}$ gives a straight line with a slope of $1 / q_{\max }$ and intercept of $1 /\left(K_{\mathrm{L}} q_{\max }\right)$. 
On the other hand, the linearized Freundlich model isotherm is represented by the following equation:

$$
\lg q_{e}=\lg K_{F}+(1 / n) \lg C_{e}
$$

where $K_{F}$ is the adsorption capacity and $1 / n$ indicates the adsorption intensity of the system. The plots of $q_{\mathrm{e}}$ versus $C_{\mathrm{e}}$ on a $\log$ scale can be plotted to determine the values of $1 / n$ and $K_{F}$ depicting the constants of the Freundlich model.

\subsection{Kinetic Studies}

Kinetic models have been proposed to determine the mechanism of the adsorption process, which provided useful data to improve the efficiency of the adsorption and feasibility of process scale-up. In the present investigation, the mechanism of the adsorption process was studied by fitting first-order and second-order reactions to the experimental data.

The pseudo-first-order model is given by the following equation:

$$
\ln \left(q_{e}-q_{t}\right)=\ln \left(q_{e}\right)-k_{1} t
$$

where $q_{e}$ and $q_{t}$ are the adsorption capacities of Cr using SDS-chitosan beads at equilibrium and time $t$, respectively $\left(\mathrm{mol} \cdot \mathrm{g}^{-1}\right)$, and $k_{1}$ is the rate constant of the pseudo-first-order adsorption $\left(\mathrm{h}^{-1}\right)$.

The linear form of the pseudo-second-order rate equation is given as follows:

$$
\frac{t}{q_{t}}=\frac{1}{k q_{e}^{2}}+\frac{t}{q_{e}}
$$

where $k$ is the rate constant of the pseudo-second-order adsorption $\left(\mathrm{g} \cdot \mathrm{mol}^{-1} \cdot \mathrm{h}^{-1}\right)$.

\subsection{Adsorption Thermodynamics}

Thermodynamic considerations of an adsorption process are necessary to investigate whether the process is spontaneous. Gibb's free energy change $\left(\Delta G^{0}\right)$ is an indication of spontaneity of the chemical reaction. Gibb's free energy of the process can be determined by both standard enthalpy $\left(\Delta H^{0}\right)$ and standard entropy $\left(\Delta S^{0}\right)$ [39-42]. The free energy of an adsorption process is related to the equilibrium constant by the Van't Hoff equation:

$$
\Delta G^{0}=-R T \ln K_{d}
$$

where $R$ is the universal gas constant $\left(8.314 \mathrm{Jmol}^{-1} \mathrm{~K}^{-1}\right)$ and $T$ is the temperature $(K)$. The value of $\ln$ $K_{\mathrm{d}}$ can be obtained by plotting $\ln \left(q_{\mathrm{e}} / C_{\mathrm{e}}\right)$ vs. $q_{\mathrm{e}}$ for the adsorption of metallic ions on SDS-chitosan and extrapolating $q_{\mathrm{e}}$ to zero [43,44]. The thermodynamic parameters of the adsorption for the equations were also calculated by using the Langmuir constant $\left(K_{\mathrm{L}}\right)$ or Freundlich constants $\left(K_{\mathrm{F}}\right)$ instead of $K_{\mathrm{d}}$.

$$
\ln K_{d}=\frac{\Delta S^{0}}{R}-\frac{\Delta H^{0}}{R T}
$$

The slope and intercept of the Van't Hoff plot of $\ln K_{d}$ vs. $1 / T$ were used to determine the values of $\Delta H^{0}$ and $\Delta S^{0}$ based on equation (6). The plot of $\Delta G^{0}$ vs. $T$ can also give $\Delta H^{0}$ and $\Delta S^{0}$ by the following equation [43-45]:

$$
\Delta G^{0}=\Delta H^{0}-T \Delta S^{0}
$$

\subsection{Effect of Competitive Anions $\left(\mathrm{Cl}^{-}, \mathrm{NO}_{2}{ }^{-}, \mathrm{NO}_{3}{ }^{-}\right.$, and $\left.\mathrm{PO}_{4}{ }^{3-}\right)$ on the Sorption of $\mathrm{Cr}(\mathrm{VI})$}

The effect of competitive anions on the sorption of $\mathrm{Cr}(\mathrm{VI})$ was studied in the following experiment. In this experiment, the initial concentration of $\mathrm{Cr}(\mathrm{VI})$ was taken as $1 \mathrm{mg} \cdot \mathrm{L}^{-1}$. Each SDS-modified chitosan $(1.0 \mathrm{~g})$ bead was placed into a $200 \mathrm{~mL}$ conical flask contacting $50 \mathrm{~mL}$ of $\mathrm{Cr}(\mathrm{VI})$ solution in the presence of chloride $\left(\mathrm{Cl}^{-}\right)$, nitrite acid $\left(\mathrm{NO}_{2}{ }^{-}\right)$, nitric acid $\left(\mathrm{NO}_{3}{ }^{-}\right)$and phosphate acid $\left(\mathrm{PO}_{4}{ }^{3-}\right)$ ions at 
different concentrations of 50, 100, and $200 \mathrm{mg} \cdot \mathrm{L}^{-1}$. Other experimental conditions ( $\mathrm{pH}$ 4, contact time $24 \mathrm{~h}$, and sorbent dosage $1.0 \mathrm{~g} \cdot \mathrm{L}^{-1}$ ) and methods were essentially the same as those mentioned above in Section 2.3 .

\subsection{Desorption Experiments}

From an industrial and technological point of view, it is desirable to recover and reuse the adsorbed material. A preliminary desorption experiment was conducted using SDS-chitosan beads after the adsorption of $\mathrm{Cr}(\mathrm{VI})$. The exhausted adsorbent was washed and dried overnight in each desorption experiment. After that, it was shaken for $24 \mathrm{~h}$ at $25^{\circ} \mathrm{C}$ in a $100 \mathrm{~mL}$ flask which contained $50 \mathrm{~mL}$ of $0.1 \mathrm{M} \mathrm{NaOH}$ solution or ultrapure water. After the system attained equilibrium, the suspension was filtered, and the $\mathrm{Cr}(\mathrm{VI})$ content in the filtrate was determined finally.

\section{Results and Discussion}

\subsection{Adsorption Experiment}

\subsubsection{Effect of SDS Loading on the Adsorption of $\mathrm{Cr}(\mathrm{VI})$}

The maximum removal of $\mathrm{Cr}(\mathrm{VI})$ by modified chitosan beads can be obtained by controlling the SDS concentration. In order to research the optimum initial concentrations of SDS loading on chitosan beads for $\mathrm{Cr}(\mathrm{VI})$ removal, the chitosan beads were modified with SDS solutions with varying initial SDS concentrations (10-6000 mg/L). The experiment was conducted under the following conditions: adsorbent dose of $0.05 \mathrm{~g}$, initial concentration of $\mathrm{Cr}(\mathrm{VI})$ of $1 \mathrm{mg} / \mathrm{L}$, $\mathrm{pH}$ of 4 , and contact time of three days. The effect of surfactant loading on chitosan beads towards $\mathrm{Cr}(\mathrm{VI})$ adsorption is shown in Figure 2. The low SDS concentrations $(0-1000 \mathrm{mg} / \mathrm{L})$ range in Figure 2a was extended and shown in Figure $2 \mathrm{~b}$. From this figure, it was found that the adsorption capacity increased with an increase in the SDS concentration from 10 to $40 \mathrm{mg} / \mathrm{L}$, and that it attained the maximum capacity at the initial SDS concentration of $40 \mathrm{mg} / \mathrm{L}$. With a higher concentration of SDS, a higher adsorption capacity could not be obtained compared to the case of a low concentration range (10 to $100 \mathrm{mg} / \mathrm{L}$ ). It is considered that the positively charged amino group was occupied by SDS, and thereby the adsorption reached saturation. Then, $40 \mathrm{mg} / \mathrm{L}$ was considered as the optimum SDS loading for further experiments.

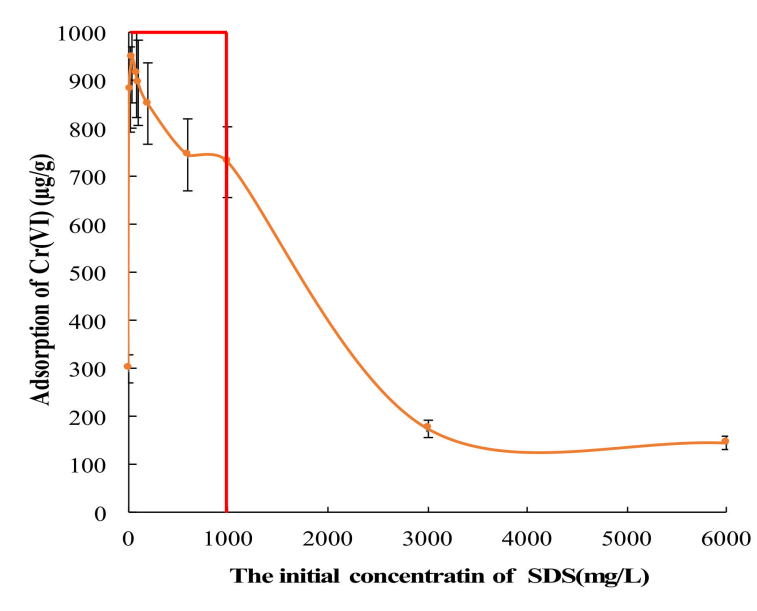

(a)

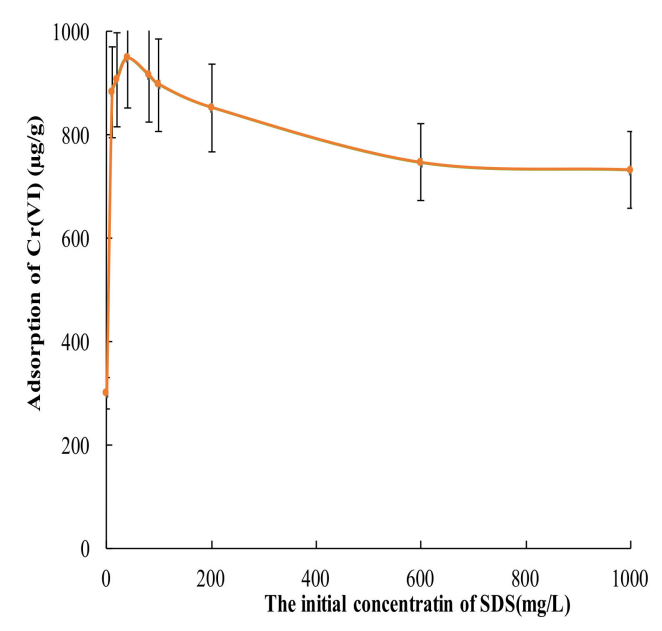

(b)

Figure 2. Adsorption of $\mathrm{Cr}(\mathrm{VI})$ for different initial SDS concentrations (10-6000 mg/L). (a) Effect of initial SDS concentrations (10-6000 mg/L) on the adsorption of chromium (Cr) (VI). (b) Effect of initial SDS concentrations (10-1000 mg/L) on the adsorption of $\mathrm{Cr}(\mathrm{VI})$. 


\subsubsection{Effect of $\mathrm{pH}$ on the Adsorption of $\mathrm{Cr}(\mathrm{VI})$}

The solution $\mathrm{pH}$ is one of the most important parameters in the adsorption process. Figure 3 shows the effect of the $\mathrm{pH}$ on $\mathrm{Cr}(\mathrm{VI})$ adsorption by SDS-modified chitosan beads. In this experiment, the shaking time was $24 \mathrm{~h}$, temperature was $25^{\circ} \mathrm{C}$, dose of adsorbent was $0.02 \mathrm{~g} / \mathrm{L}$, and initial $\mathrm{Cr}(\mathrm{VI})$ concentration was $1 \mathrm{mg} / \mathrm{L}$. The acidity of the solution had a significant effect on the adsorption of SDS-modified chitosan beads towards $\mathrm{Cr}(\mathrm{VI})$, where the amino groups of chitosan were protonated and positively charged. Moreover, the sulfate group is a typical strong acid group. Therefore, even under the acidic condition, which would not easily hydrolyze with water, surfactants could behave fully in their anionic form. It is well-known that chitosan molecules are protonated at amino groups which carry cationic adsorption sites and that they are dissolved in the acidic region [36]. Apart from cationic amino groups, chitosan chain adsorption (leading to interparticle bridging) can also occur through hydrogen bonds [46]. Similar to cationic polyacrylamide, chitosan is, thus, able to aggregate anionic soluble compounds (through electrostatic affinities) and simultaneously flocculate particulate matter through interparticle bridging mechanisms. However, the protonation of amino groups (i.e., the effective charge density of the chitosan polymer chain) can be influenced by the $\mathrm{pH}$ [47]. This makes it impossible to conduct adsorption experiments at $\mathrm{pH}$ levels of 1-3. The effect of $\mathrm{pH}$ on the adsorption of $\mathrm{Cr}(\mathrm{VI})$ by SDS-modified chitosan beads was estimated by adjusting the $\mathrm{pH}$ in the range of 4 to 10 (Figure 3). The maximum uptake of $\mathrm{Cr}(\mathrm{VI})$ ions took place at $\mathrm{pH} 4-5$, which may be attributable to the changes in the surface charge of the adsorbent. With an increase of the $\mathrm{pH}$ at above pH 5, the uptake decreased.

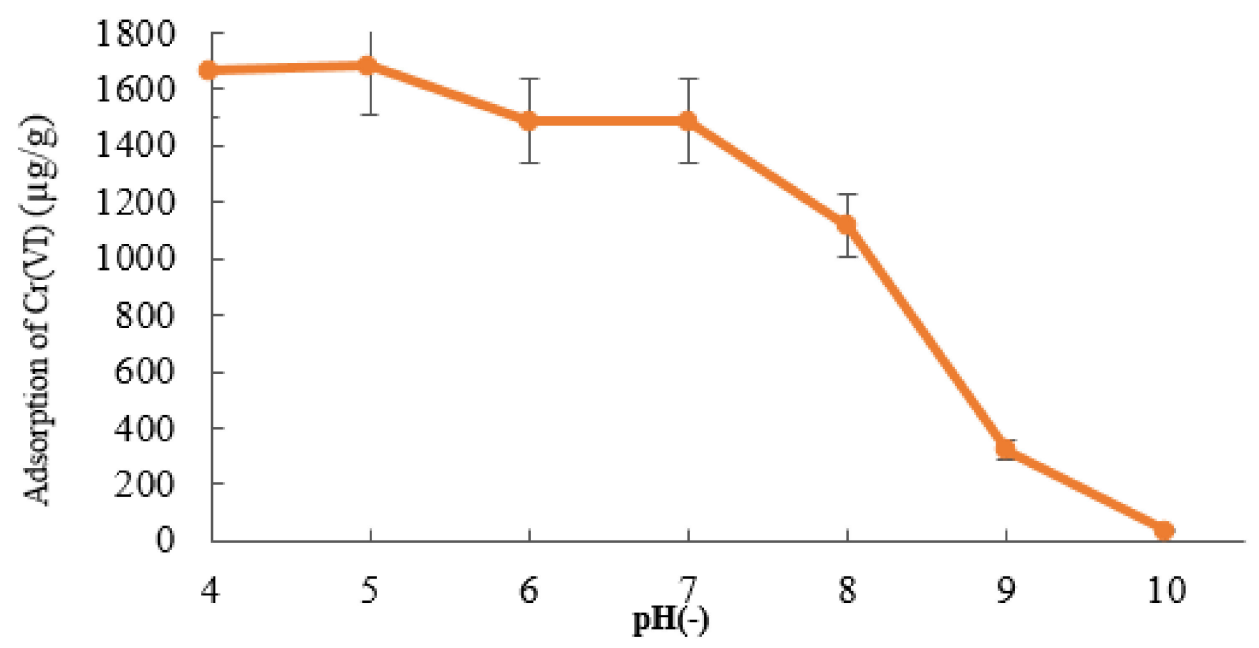

Figure 3. Effect of $\mathrm{pH}$ on the adsorption of $\mathrm{Cr}(\mathrm{VI})$ onto the SDS-modified chitosan beads.

$\mathrm{Cr}(\mathrm{VI})$ may be present in the form of $\mathrm{HCrO}_{4}{ }^{-}$and $\mathrm{CrO}_{4}{ }^{2}$. As shown in Figure $4, \mathrm{HCrO}_{4}{ }^{-}$is dominant in the $\mathrm{pH}$ range of $2-4$. However, $\mathrm{CrO}_{4}{ }^{2-}$ becomes increasingly dominant as the solution becomes more basic, and the form of $\mathrm{CrO}_{4}{ }^{2-}$ becomes stable above the $\mathrm{pH}$ of 7 [32]. The following equations indicate the shift process of $\mathrm{Cr}(\mathrm{VI})$ species:

$$
\begin{gathered}
\mathrm{HCrO}_{4}{ }^{-} \leftrightarrow \mathrm{CrO}_{4}{ }^{2-}+\mathrm{H}^{+} \mathrm{pKa}=5.9 \\
\mathrm{H}_{2} \mathrm{CrO}_{4} \leftrightarrow \mathrm{HCrO}_{4}^{-}+\mathrm{H}^{+} \mathrm{pKa}=4.1 \\
\mathrm{Cr}_{2} \mathrm{O}_{7}{ }^{2-}+\mathrm{H}_{2} \mathrm{O} \leftrightarrow 2 \mathrm{HCrO}_{4}^{-} \mathrm{pKa}=2.2
\end{gathered}
$$




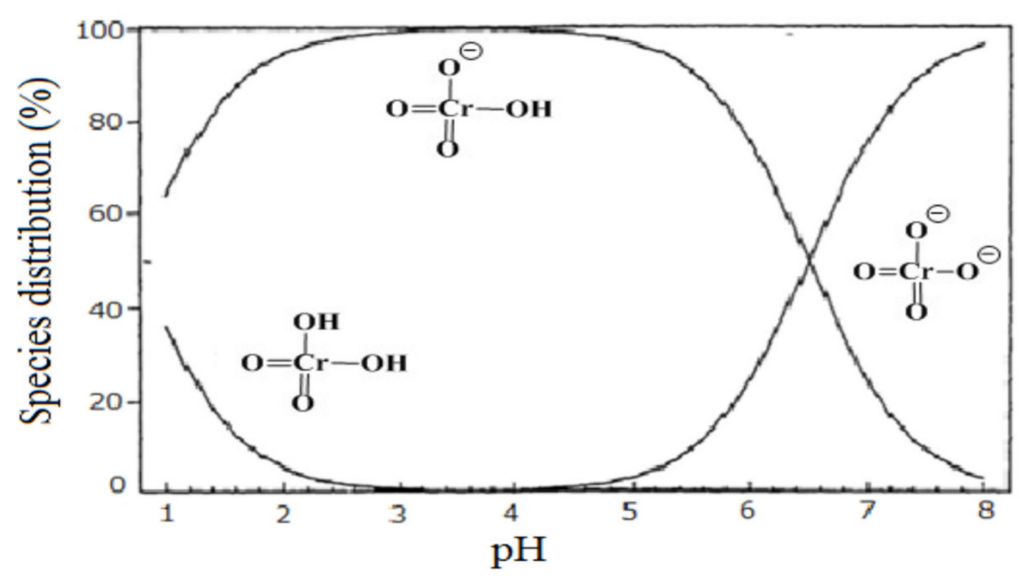

Figure 4. Species distribution curves of $\mathrm{Cr}(\mathrm{VI})$ in environmental water [32].

From these results, the functional groups combining with chromate ions may decrease due to the increase in their ion valence. It is supposed that amino acids with a positive charge combine with hydroxyl ions after binding with protons. Therefore, the adsorption capacity can largely depend on the kind of functional group and the existing form of $\mathrm{Cr}(\mathrm{VI})$. The surface of the SDS-chitosan beads became positively charged, owing to strong protonation in these $\mathrm{pH}$ ranges. This led to a stronger attraction between the positively charged surface and the negatively charged $\mathrm{Cr}_{2} \mathrm{O}_{7}{ }^{2-}$ or $\mathrm{HCrO}_{4}{ }^{-}$.

\subsubsection{Effect of Contact Time on the Adsorption of $\mathrm{Cr}(\mathrm{VI})$}

The effect of the contact time on the adsorption capacity of $\mathrm{Cr}(\mathrm{VI})$ by SDS-modified chitosan beads was explored. In this experiment, the concentration of $\mathrm{Cr}(\mathrm{VI})$ was set as $1 \mathrm{mg} / \mathrm{L}$ with the dose of $0.05 \mathrm{~g}$ at a temperature of $25^{\circ} \mathrm{C}$. The $\mathrm{pH}$ of the solution was kept at 4 , in order to achieve the maximum removal of $\mathrm{Cr}(\mathrm{VI})$. Figure 5 demonstrates the adsorption of $\mathrm{Cr}(\mathrm{VI})$ with varying contact times from 1 to $96 \mathrm{~h}$.

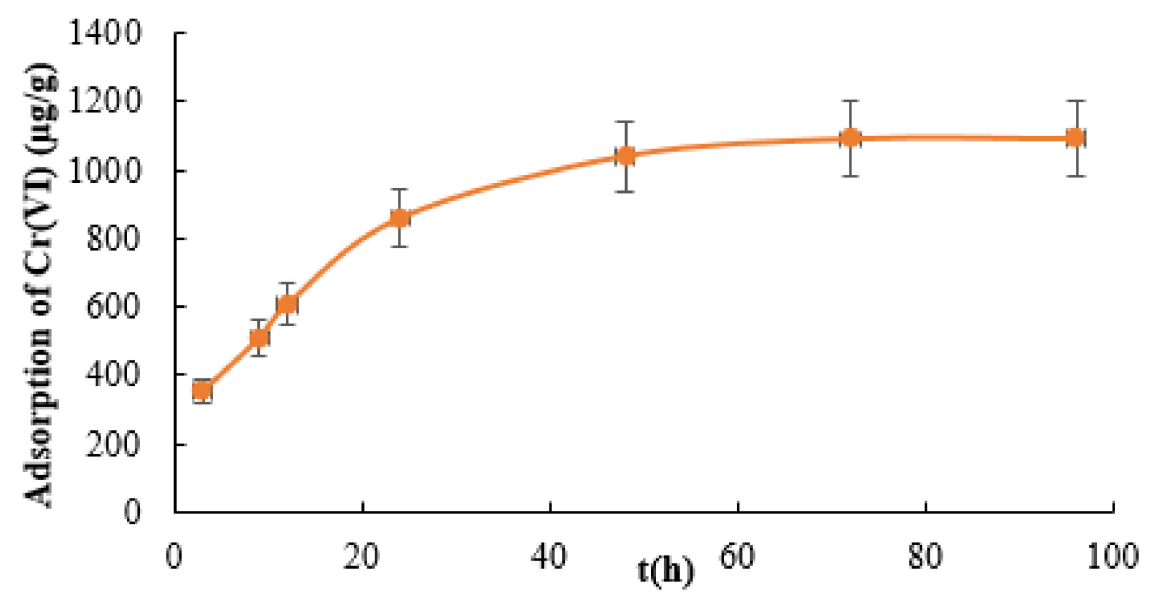

Figure 5. Effect of the contact time on the adsorption of $\mathrm{Cr}(\mathrm{VI})$ on the SDS-modified chitosan beads.

The adsorption capacity of SDS-chitosan beads for $\mathrm{Cr}(\mathrm{VI})$ increased sharply within the first $24 \mathrm{~h}$, which may be attributable to the availability of the sites on the surface of the adsorbent. It is suggested that a concentration gradient is present in both the adsorbent and adsorbate in the solution [48]. Then, it reached adsorption equilibrium at $72 \mathrm{~h}$, and afterwards, there was no appreciable increase (Figure 5). Hence, the optimized contact time was taken to be $72 \mathrm{~h}$ for further studies. The surface modification of the chitosan beads by SDS facilitates the adsorption through an ion-exchange mechanism [38]. Usually, the complexation mechanisms involve slower kinetics than the ion-exchange and hydrogen bonding reaction mechanism [49-51]. 


\subsubsection{Effect of the Adsorbent Dosage on the Adsorption of $\mathrm{Cr}(\mathrm{VI})$}

To determine the effect of the adsorbent dosage on the removal of $\mathrm{Cr}(\mathrm{VI})$, the experiments were carried out by varying the dosage (from 0.4 to $1.0 \mathrm{mg} / \mathrm{L}$ ) and keeping all other parameters constant (temperature: $25^{\circ} \mathrm{C}$; $\mathrm{pH}$ : 4; contact time: $24 \mathrm{~h}$; initial concentration: $1.0 \mathrm{mg} / \mathrm{L}$ ). The results are shown in Figure 6. The removal of more than $80 \% \mathrm{Cr}(\mathrm{VI})$ was observed for the $0.8 \mathrm{mg} / \mathrm{L}$ dosage, but no notable increase was observed at a dosage of more than $0.8 \mathrm{mg} / \mathrm{L}$. Therefore, $0.8 \mathrm{mg} / \mathrm{L}$ was regarded as the optimum dosage for the removal of $\mathrm{Cr}(\mathrm{VI})$ in this study. A higher dose provides a larger number of binding sites, which eventually causes the enhanced removal of $\mathrm{Cr}(\mathrm{VI})$.

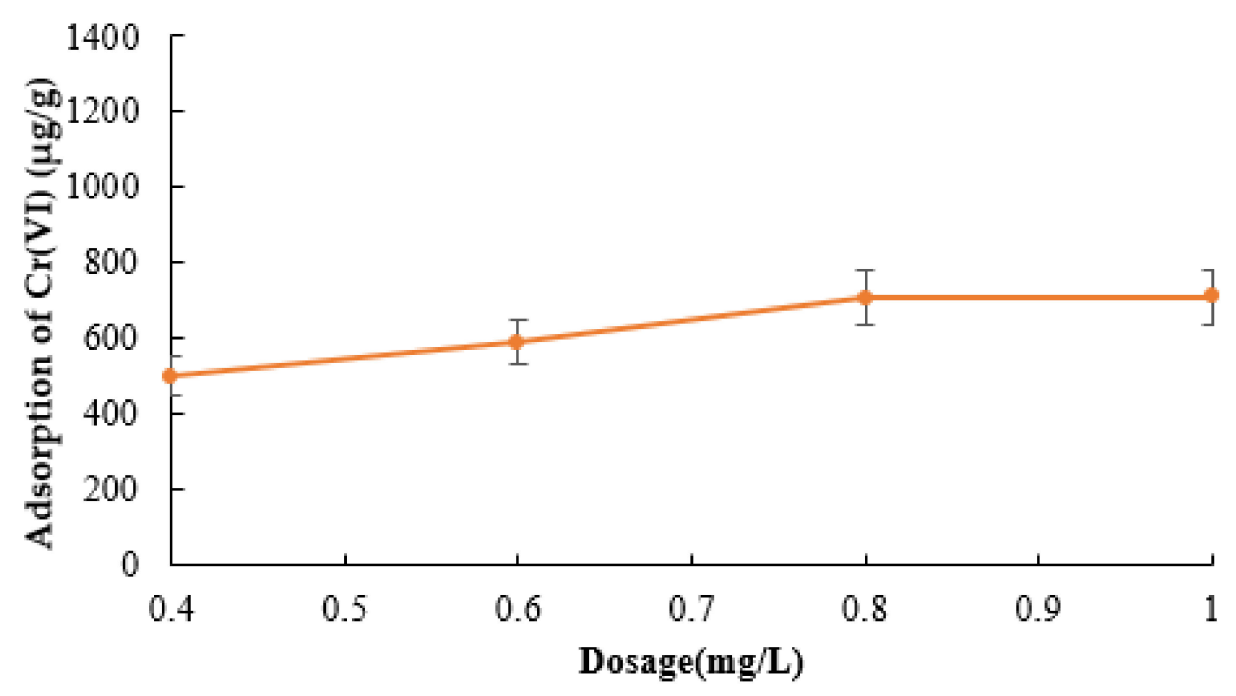

Figure 6. Effect of the adsorbent dosage on the adsorption of $\mathrm{Cr}(\mathrm{VI})$ on the SDS-modified chitosan beads.

\subsubsection{Effect of Coexisting Ions on the Adsorption of $\mathrm{Cr}(\mathrm{VI})$}

The effect of competitive anions on the adsorption of $\mathrm{Cr}(\mathrm{VI})$ is shown in Figure 7. In this experiment, the initial concentration of $\mathrm{Cr}(\mathrm{VI})$ was set as $1 \mathrm{mg} \cdot \mathrm{L}^{-1}$. These counter ions were tested collectively, and all various ions were included at 50,100, or $200 \mathrm{mg} / \mathrm{L}$ in solution. From this figure, the removal of $\mathrm{Cr}(\mathrm{VI})$ was remarkably decreased under the presence of common ions at above $50 \mathrm{mg}$. $\mathrm{L}^{-1}$ (i.e., 50 times the $\mathrm{Cr}(\mathrm{VI})$ concentration or more), although no large decrease was observed when the concentration of each common ion was below $10 \mathrm{mg} \cdot \mathrm{L}^{-1}$ in our former preliminary experiments. Both $\mathrm{Cr}(\mathrm{VI})$ and other competitive anions may be attracted to the amino group by the electrostatic force. Therefore, $\mathrm{Cr}(\mathrm{VI})$ was shown to be inhibited by adsorption when the concentrations of coexisting ions were large.

\subsubsection{Estimation of Partition Coefficient (PC)}

Many adsorption studies have shown that the adsorption performance is usually evaluated and expressed by the maximum (or equilibrium) adsorption capacity. However, the maximum adsorption capacity is sensitively influenced by the initial concentration of the target pollutant (or expressing in more detail, what is left after the sorption reaction) $[52,53]$. When the sorbent is exposed to a higher concentration of objective targets, it is likely to exhibit a higher adsorption capacity. On the other hand, when the sorbent is exposed to lower levels of target species, it will show lower capacities. Therefore, in addition to the maximum adsorption capacity, it is effective to estimate using the concept of the partition coefficient (PC-adsorption capacity/final concentration) [53,54]. Comprehensive experimental data of the adsorption process under different effect factors are shown in Table 2. The data in Table 2 correspond to the data from Section 3.1.1. to Section 3.1.4. (i.e., Figures 2, 3, 5 and 6). From Table 2, it could be found that the adsorption affinity was fairly good under the following conditions when using either the concept of the adsorption capacity or that of the PC: $\mathrm{pH}$ of 4-5, contact time of $72 \mathrm{~h}$, initial concentration of SDS $40 \mathrm{mg} \cdot \mathrm{L}^{-1}$, and adsorbent dose of $0.8-1.0 \mathrm{mg} \cdot \mathrm{L}^{-1}$. 


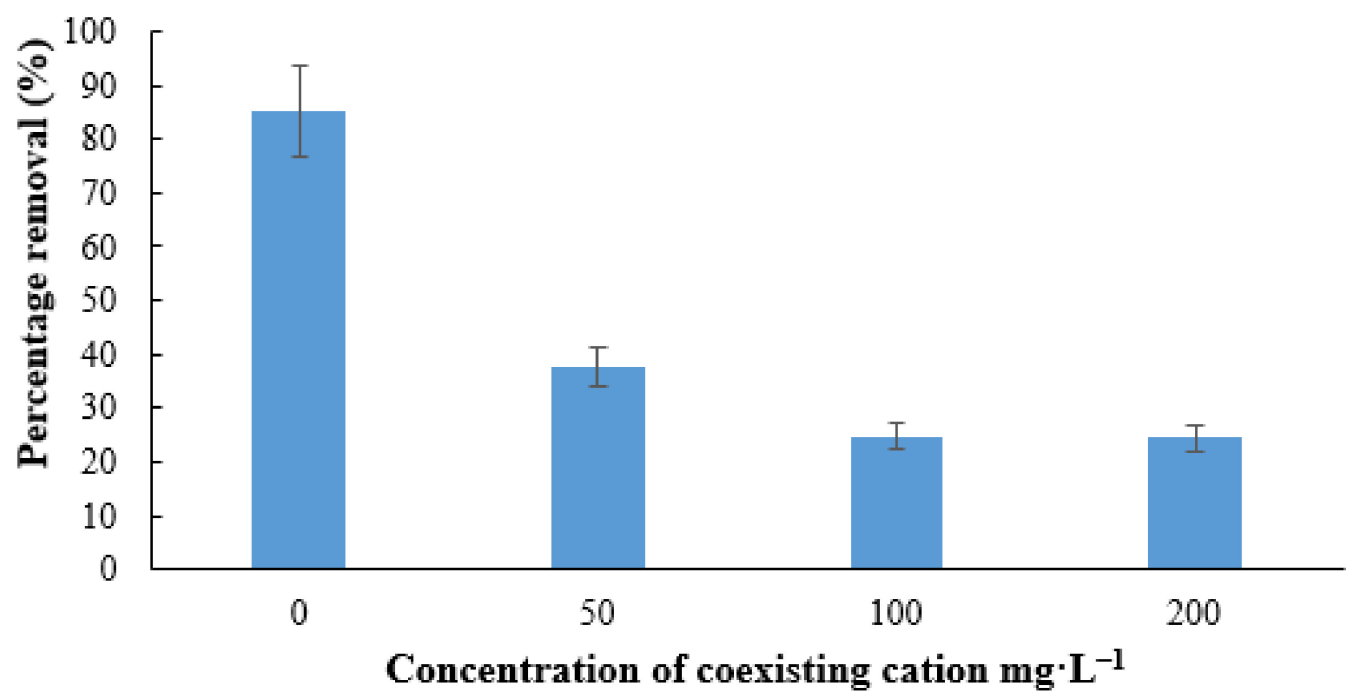

Figure 7. Effect of competitive anions on the adsorption of $\mathrm{Cr}(\mathrm{VI})$ on the SDS-modified chitosan beads.

Table 2. Detailed experimental data of the adsorption process under different effect factors.

\begin{tabular}{|c|c|c|c|c|c|c|}
\hline \multirow[t]{2}{*}{ Target Ions } & \multirow[t]{2}{*}{ Adsorbent } & \multirow[t]{2}{*}{ Effect Factor } & \multicolumn{2}{|c|}{$\begin{array}{c}\text { Final Concentration } \\
\left(\mu \mathrm{g} \cdot \mathrm{L}^{-1}\right)\end{array}$} & \multirow{2}{*}{$\begin{array}{c}\begin{array}{c}\text { Adsorption } \\
\text { Capacity } \\
\left(\mu \mathrm{g} \cdot \mathrm{g}^{-\mathbf{1}}\right)\end{array} \\
1665.39\end{array}$} & \multirow{2}{*}{$\begin{array}{c}\begin{array}{c}\text { Adsorption } \\
\text { Capacity/ Final } \\
\text { Concentration }(\mathrm{PC}) \\
\left(\mu \mathrm{g} \cdot \mathrm{g}^{-\mathbf{1}} \cdot \boldsymbol{\mu} \mathbf{M}^{-1}\right)\end{array} \\
0.034\end{array}$} \\
\hline & & & 4 & 966.69 & & \\
\hline \multirow{26}{*}{$\mathrm{Cr}(\mathrm{VI})$} & \multirow{26}{*}{ SDS } & \multirow{6}{*}{$\mathrm{pH}$} & 5 & 966.37 & 1681.62 & 0.035 \\
\hline & & & 6 & 970.3 & 1484.99 & 0.031 \\
\hline & & & 7 & 970.24 & 1488.23 & 0.031 \\
\hline & & & 8 & 977.8 & 1114.81 & 0.022 \\
\hline & & & 9 & 993.55 & 322.60 & 0.0065 \\
\hline & & & 10 & 999.29 & 35.87 & 0.00071 \\
\hline & & \multirow{7}{*}{$\begin{array}{l}\text { Contact time } \\
\text { (h) }\end{array}$} & 3 & 982.28 & 354.31 & 0.018 \\
\hline & & & 9 & 974.53 & 509.35 & 0.026 \\
\hline & & & 12 & 969.69 & 606.23 & 0.031 \\
\hline & & & 24 & 957.04 & 859.12 & 0.045 \\
\hline & & & 48 & 948 & 1039.91 & 0.055 \\
\hline & & & 72 & 945.51 & 1089.86 & 0.058 \\
\hline & & & 96 & 945.50 & 1090.21 & 0.058 \\
\hline & & \multirow{4}{*}{ Initial } & 0 & 985 & 300 & 0.015 \\
\hline & & & 10 & 955.93 & 881.49 & 0.046 \\
\hline & & & 20 & 954.67 & 906.69 & 0.047 \\
\hline & & & 40 & 952.63 & 947.37 & 0.050 \\
\hline & & \multirow{5}{*}{$\begin{array}{l}\text { Concentration } \\
\text { of SDS } \\
\left(\mathrm{mg} \cdot \mathrm{L}^{-1}\right)\end{array}$} & 80 & 954.25 & 915.02 & 0.048 \\
\hline & & & 100 & 955.20 & 896.11 & 0.047 \\
\hline & & & 200 & 957.41 & 851.81 & 0.044 \\
\hline & & & 600 & 962.73 & 745.33 & 0.039 \\
\hline & & & 1000 & 963.44 & 731.16 & 0.038 \\
\hline & & \multirow{4}{*}{$\begin{array}{c}\text { Dose } \\
\left(\mathrm{mg} \cdot \mathrm{L}^{-1}\right)\end{array}$} & 0.4 & 800 & 500 & 0.4 \\
\hline & & & 0.6 & 646.6 & 589 & 0.86 \\
\hline & & & 0.8 & 434.4 & 707 & 1.93 \\
\hline & & & 1.0 & 292 & 708 & 2.42 \\
\hline
\end{tabular}

\subsection{Characterization of SDS Modified Chitosan}

The SEM-EDS images of chitosan beads and SDS-chitosan beads ( $40 \mathrm{mg} / \mathrm{L} \mathrm{SDS}$ loading) are shown in Figure 8. From SEM images, it could be determined that the diameter of these beads was roughly $800 \mu \mathrm{m}$. These figures show that the surface of the membrane appears concave and convex. This may be attributable to the loss of water (about 98\%) contained in the sorbent upon the drying of chitosan. It is considered that adsorption proceeded with physical and chemical adsorption. From the mapping images, it is shown that $\mathrm{Cr}$ ions were sufficiently adsorbed on the adsorbent. 

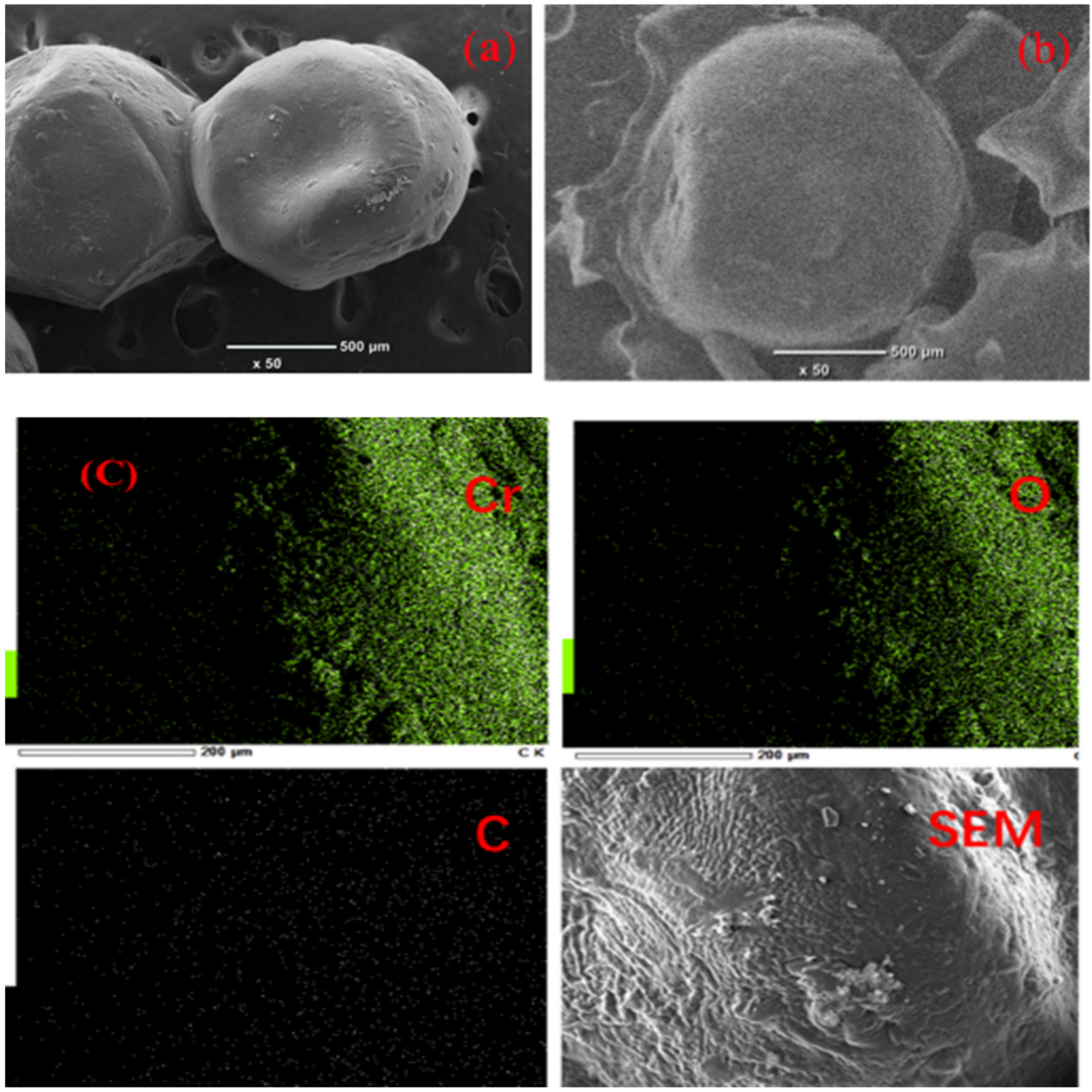

Figure 8. Scanning electron microscopy (SEM) images of (a) chitosan beads and (b) SDS-modified chitosan beads, and (c) mapping image of SDS-modified chitosan beads after the adsorption of $\mathrm{Cr}(\mathrm{VI})$.

The FT-IR spectra of the chitosan and SDS-chitosan beads are exhibited in Figure 9. The broad and intense peak at 3400 to $3500 \mathrm{~cm}^{-1}$ corresponds to $\mathrm{O}-\mathrm{H}$ and $-\mathrm{NH}_{2}$ stretching vibrations of hydroxyl groups of chitosan and SDS-chitosan [55-57]. The peak at $2871 \mathrm{~cm}^{-1}$ is related to the aliphatic methylene group [58,59]. The wide peaks at 1560 to $1640 \mathrm{~cm}^{-1}$ and $1110 \mathrm{~cm}^{-1}$ show the imine group and ether group [57]. The SDS-modified chitosan bands at around $1248 \mathrm{~cm}^{-1}$ are characteristic of the asymmetrical vibrations of the C-O-S group $[59,60]$. The adsorbent could be identified as a composite of SDS and chitosan.

XPS analysis was employed to survey the chemical compositions and binding condition of the surface on the samples. Chitosan beads with different amounts of SDS loading were analyzed (Figure 10a-Chitosan; Figure 10b-SDS100-chitosan; Figure 10c-SDS600-chitosan; Figure 10d-SDS6000-chitosan). As can be seen in Figure 10, the C1s spectra of these samples displayed peaks at $284.5 \mathrm{eV}$ and 286.5 and $288.5 \mathrm{eV}$, corresponding to $\mathrm{C}-\mathrm{C}$ bonds $\mathrm{C}-\mathrm{O}$ and $\mathrm{C}=\mathrm{O}$, respectively. It also shows that the S 2p spectra of SDS600-chitosan and SDS6000-chitosan displayed peaks at $169 \mathrm{eV}$. From Table 3, it could be found that the predominant elements were carbon and oxygen, and that the SDS100-chitosan and SDS600-chitosan atomic values of the N element are $1.75 \%$ and $1.69 \%$, respectively. The SDS600-chitosan and SDS6000-chitosan atomic values of the S element are $2.78 \%$ and $6.85 \%$ respectively, which suggests that the higher the concentration of loading SDS is, the higher the concentration of the $\mathrm{S}$ element is. 


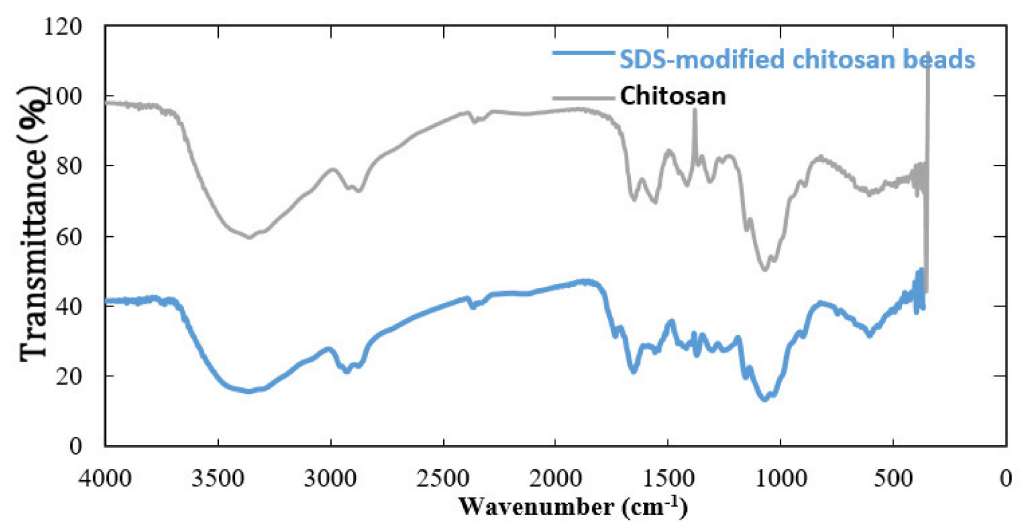

Figure 9. Fourier transform-infrared spectroscopy (FT-IR) spectra of chitosan and SDS-modified chitosan beads.

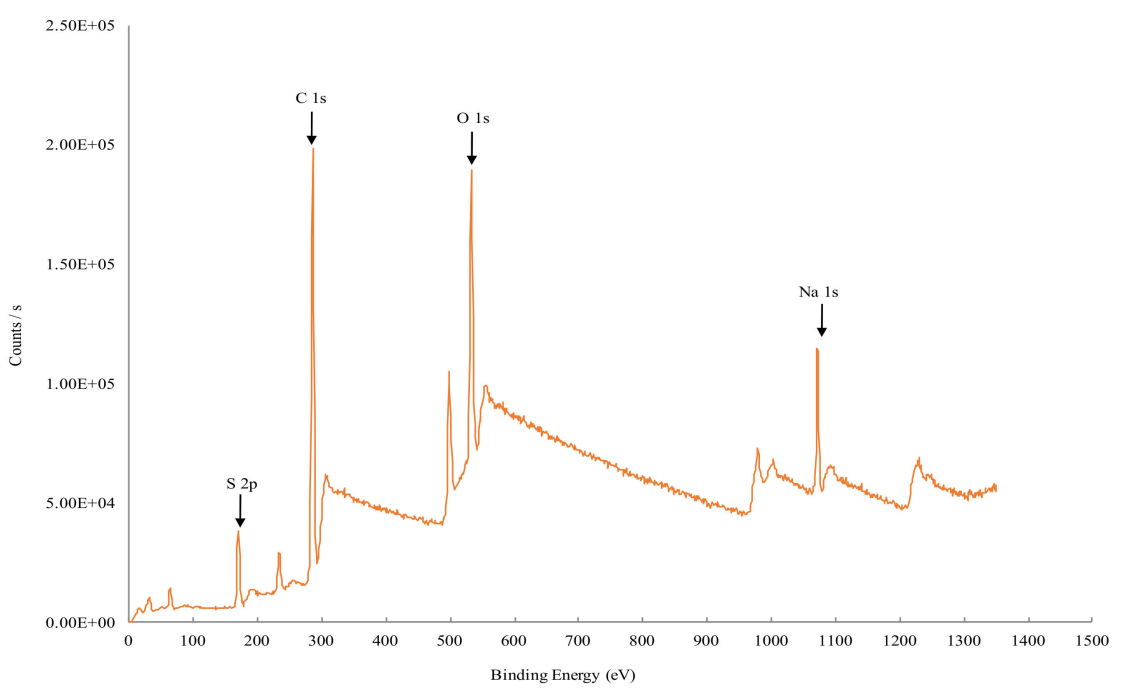

(a)

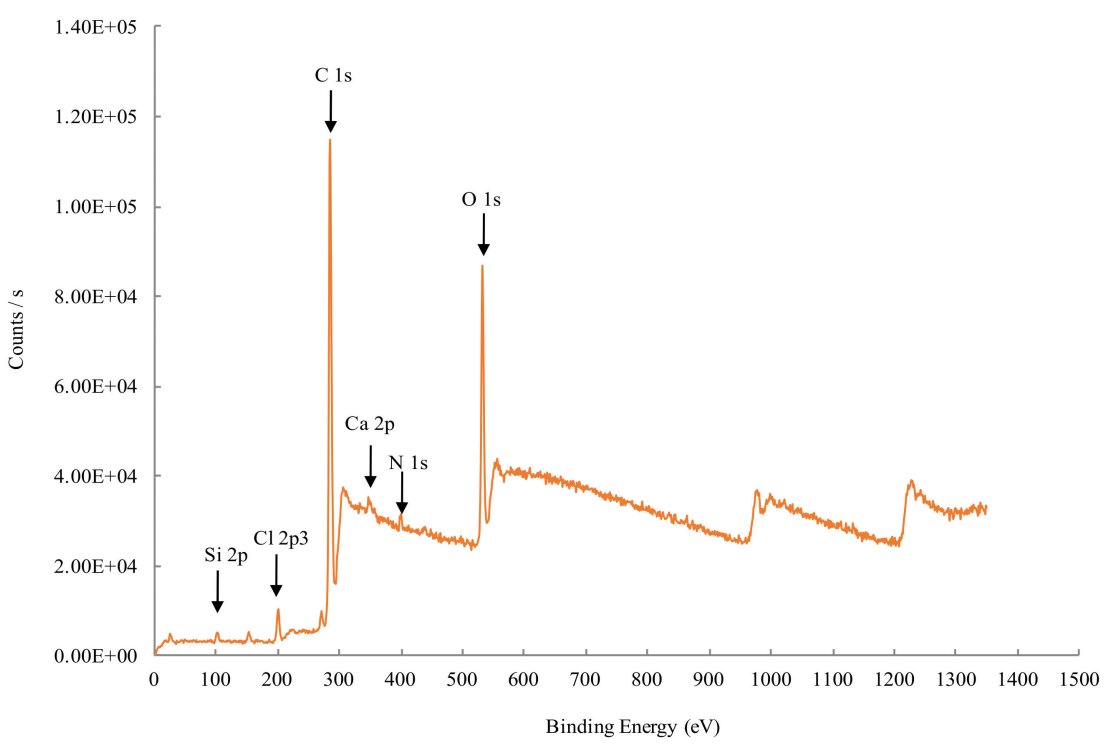

(b)

Figure 10. Cont. 


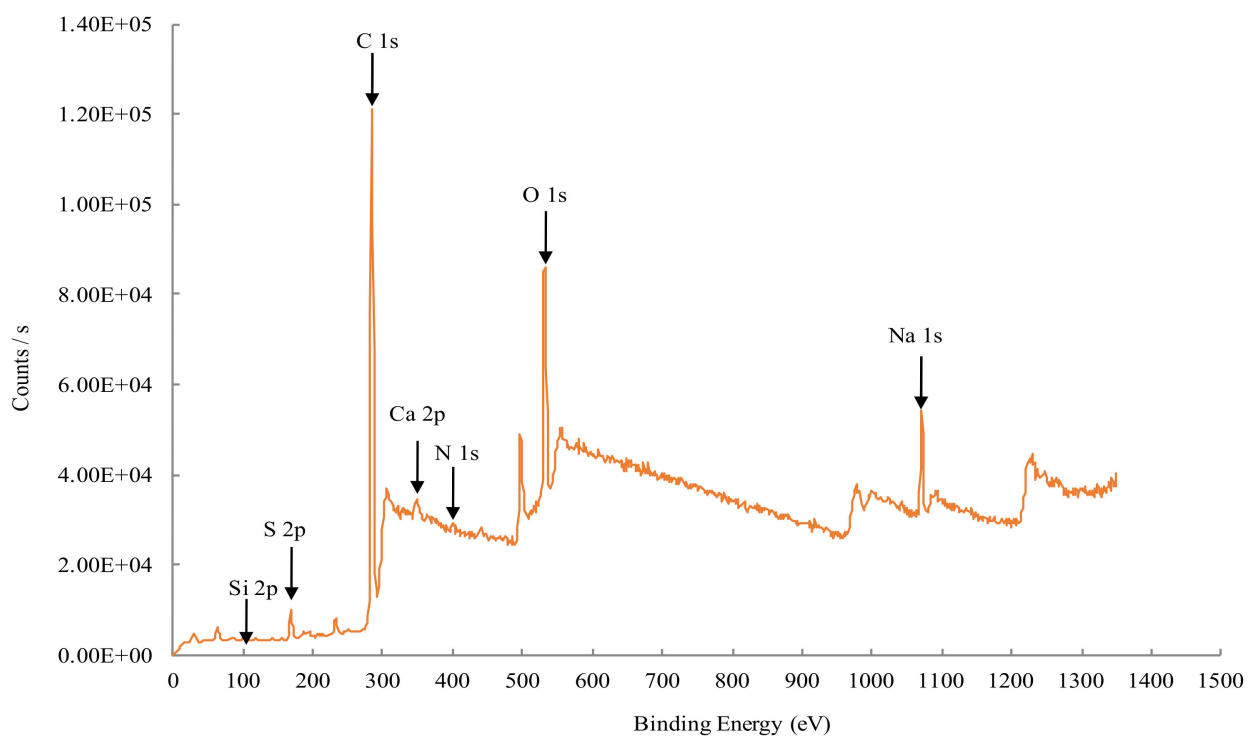

(c)

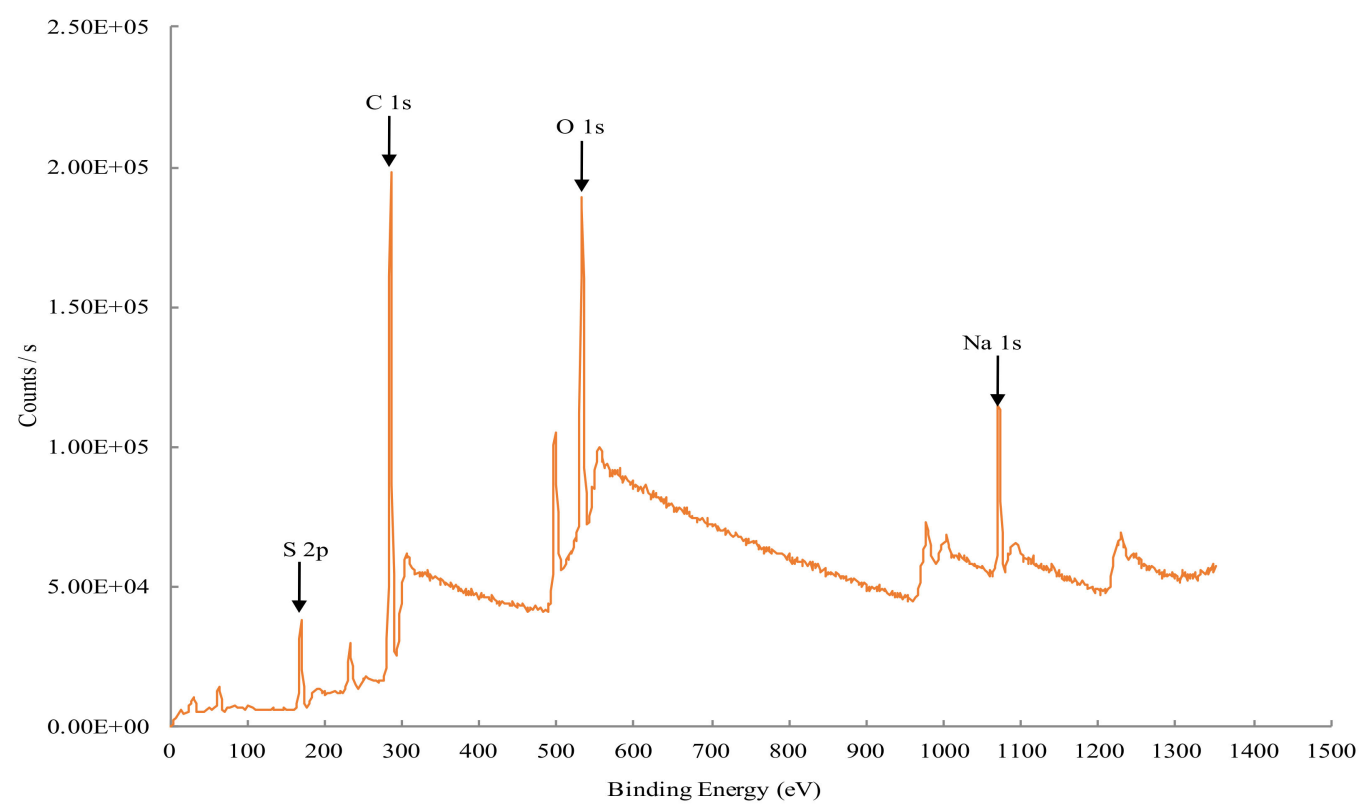

(d)

Figure 10. X-ray photoelectron spectroscopy (XPS) spectra of (a) chitosan, (b) SDS100-chitosan, (c) SDS600-chitosan, and (d) SDS6000-chitosan beads.

Table 3. Atomic ratio of each chitosan bead obtained by XPS analysis.

\begin{tabular}{ccccc}
\hline $\begin{array}{c}\text { Name } \\
\text { Atomic\% }\end{array}$ & Chitosan & $\begin{array}{c}\text { SDS100 } \\
\text {-Chitosan }\end{array}$ & $\begin{array}{c}\text { SDS600 } \\
\text {-Chitosan }\end{array}$ & $\begin{array}{c}\text { SDS6000 } \\
\text {-Chitosan }\end{array}$ \\
\hline Si 2p & 4.41 & 2.06 & 0.81 & \\
S 2p & & & 2.78 & 6.85 \\
C 1s & 77.1 & 76.52 & 75.91 & 67.66 \\
Cl 2p3 & 3.94 & 3.55 & & \\
Ca 2p & 0.27 & 0.33 & 1.1 & \\
N 1s & & 1.75 & 1.69 & \\
O 1s & 14.27 & 15.78 & 14.34 & 20.19 \\
\hline
\end{tabular}




\subsection{Adsorption Isotherms}

Adsorption isotherms of $\mathrm{Cr}(\mathrm{VI})$ on SDS-chitosan beads were studied with varying initial concentrations from 0.010 to $3.0 \mathrm{mg} / \mathrm{L}$, under optimized conditions in terms of the $\mathrm{pH}(\mathrm{pH} 4)$, contact time $(72 \mathrm{~h})$, and dosage of the adsorbent $(0.8 \mathrm{mg} / \mathrm{L})$ at $298 \mathrm{~K}$ in this work. Adsorption isotherms are generally used to reflect the performance of adsorbents in adsorption processes. Herein, two common adsorption models, consisting of Langmuir [61,62] and Freundlich [61,63] equations, were employed to explain the adsorption of Cr by SDS-chitosan beads (Figure 11). The adsorption data acquired for $\mathrm{Cr}(\mathrm{VI})$ using SDS-chitosan beads were investigated by Langmuir and Freundlich equations, and the results are shown in Figures 12 and 13, respectively. All isotherm parameters calculated from the two models are listed in Table 4, along with the correlation coefficients $\left(R^{2}\right)$. High correlation coefficients indicate that $\mathrm{Cr}(\mathrm{VI})$ sorption can be well-described by the Langmuir and Freundlich isotherms. In particular, the Langmuir model was preferable, and the maximum adsorption capacity was estimated to be $3.23 \mathrm{mg} / \mathrm{g}$. The Langmuir isotherm model is known to elucidate the monolayer adsorption on homogeneous surfaces. The results implied that the adsorption of $\mathrm{Cr}(\mathrm{VI})$ was a monolayer coverage process [64]. This indicated a strong potential in the application of SDS-chitosan beads for $\mathrm{Cr}(\mathrm{VI})$ removal from an aqueous phase. On the other hand, it was found that the $R^{2}$ value obtained from the Freundlich model was not small, and favorable adsorption was suggested, judging from the value of $1 / n$ [65]. The isotherm parameters revealed that the SDS-chitosan bead with special structures could efficiently enhance the adsorption capacities.

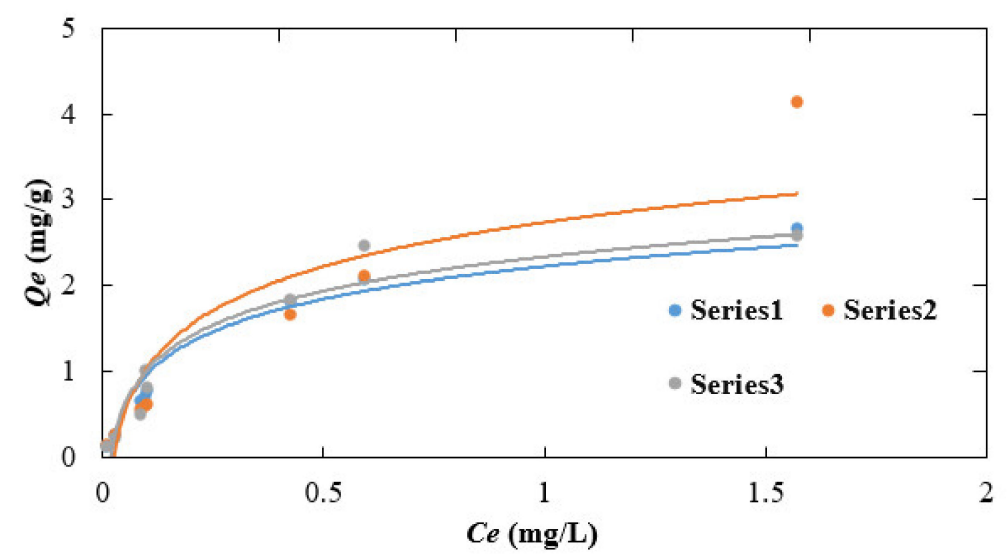

Figure 11. Adsorption isotherms of $\mathrm{Cr}(\mathrm{VI})$ using the SDS-chitosan beads.

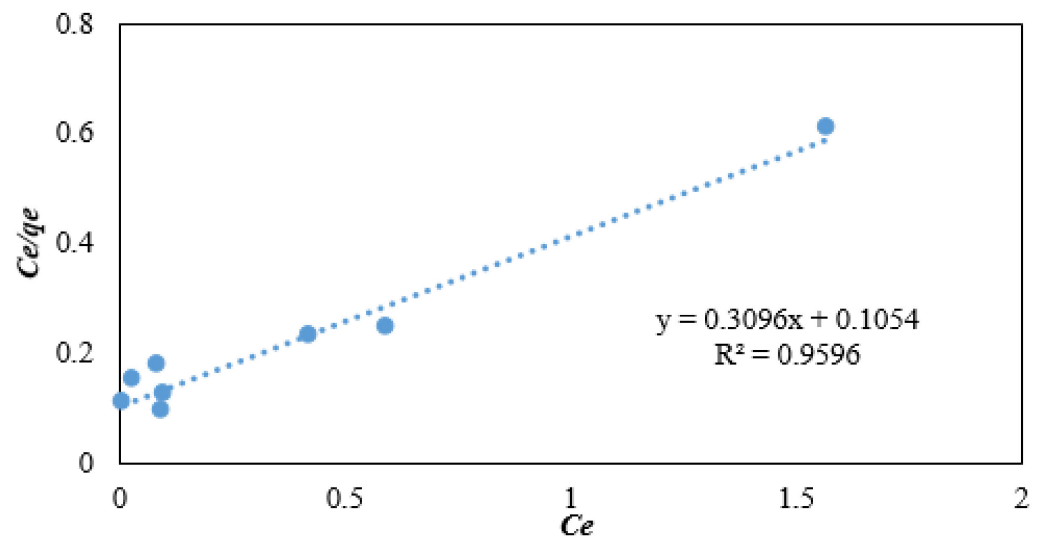

Figure 12. The Langmuir isotherm of $\mathrm{Cr}(\mathrm{VI})$ adsorption on the SDS-chitosan beads. 


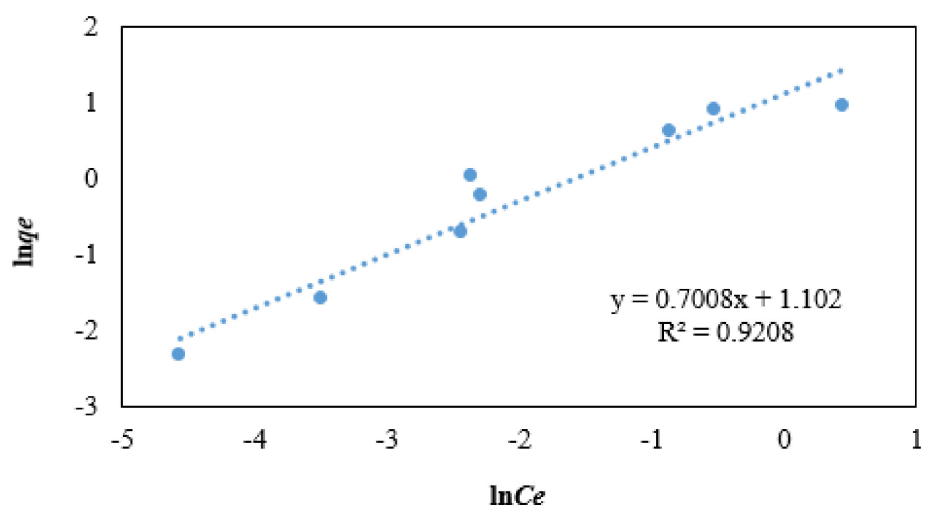

Figure 13. The Freundlich isotherm of $\mathrm{Cr}(\mathrm{VI})$ adsorption on the SDS-chitosan beads.

Table 4. Isotherm parameters for $\mathrm{Cr}(\mathrm{VI})$ adsorption onto the SDS beads.

\begin{tabular}{cccccccc}
\hline \multirow{2}{*}{ Metal } & \multirow{2}{*}{$\mathrm{T}\left({ }^{\circ} \mathrm{C}\right)$} & \multicolumn{4}{c}{ Langmuir Isotherm } & \multicolumn{3}{c}{ Freundlich Isotherm } \\
& & $Q_{\max }(\mathbf{m g} / \boldsymbol{g})$ & $\boldsymbol{R}_{\boldsymbol{L}}$ & $\boldsymbol{R}^{\mathbf{2}}$ & $\boldsymbol{K}_{\boldsymbol{F}}(\mathrm{mg} / \boldsymbol{g})$ & $\mathbf{1} \boldsymbol{n}$ & $\boldsymbol{R}^{\mathbf{2}}$ \\
\hline $\mathrm{Cr}(\mathrm{VI})$ & 25 & 3.23 & $0.308 \times 10^{-4}$ & 0.960 & 3.01 & 0.700 & 0.921 \\
\hline
\end{tabular}

\subsection{Kinetic Studies}

An adsorption kinetics study was conducted to explore the relationship between the adsorption amount $q_{\mathrm{t}}$ and time $t$. According to Figure 14, the adsorption content of $\mathrm{Cr}(\mathrm{VI})$ by SDS-chitosan beads increased significantly within $96 \mathrm{~h}$. The quick adsorption within the initial $24 \mathrm{~h}$ indicated that uptake of $\mathrm{Cr}(\mathrm{VI})$ was mainly caused by chemical sorption or surface complexation. This might be associated with the abundant exposure of sorption sites on the adsorbent surface. As the sorption sites were gradually occupied by $\mathrm{Cr}(\mathrm{VI})$, the adsorption rate of $\mathrm{Cr}(\mathrm{VI})$ became slower with a lapse of time and ultimately, approached equilibrium [66,67].

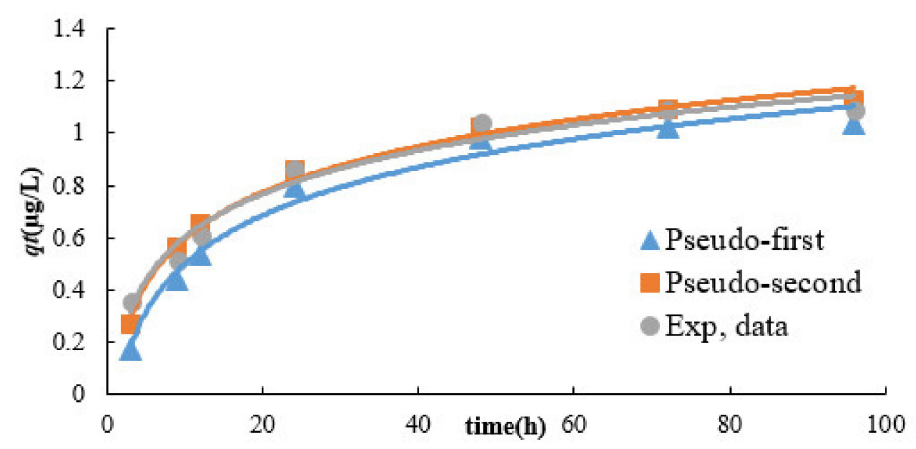

Figure 14. Pseudo-first-order and pseudo-second-order plot of $\mathrm{Cr}(\mathrm{VI})$ adsorption on the SDS-chitosan beads.

For the purpose of comprehending the adsorption kinetics in more detail, the pseudo-first-order, pse For the purpose of comprehending the adsorption kinetics in more detail, the pseudo-first-order, pseudo-second-order, and intraparticle diffusion kinetic models were applied to explain the kinetic sorption process $[68,69]$. The fitting curves of pseudo-first-order and pseudo-second-order models are presented in Figures 15 and 16, respectively. The calculated parameters, along with the correlation coefficient $\left(R^{2}\right)$ of these models, are presented in Table 5. The adsorption kinetics based on the experimental values were both in good agreement with the pseudo-first-order and pseudo-second-order kinetic models judging from the high correlation coefficients. The fitness of the pseudo-first-kinetic model implied that the rate-controlling step might involve chemisorption or chemical bonding between $\mathrm{Cr}(\mathrm{VI})$ and the functional groups of adsorbents. On the other hand, the rapid phase in the initial step 
of the adsorption process may imply physical adsorption or exchange at the adsorbent surface [61,70]. Although the adsorption data could be well-described by the pseudo-first-kinetic model, the diffusion of $\mathrm{Cr}(\mathrm{VI})$ into pores could play an important role for $\mathrm{Cr}(\mathrm{VI})$ adsorption on the adsorbent, since SDS-chitosan beads are porous structures. Therefore, an intraparticle diffusion model was also applied to elucidate the diffusion mechanism and to investigate whether the film or pore diffusion was the controlling step in the adsorption process. The plots of $q_{\mathrm{t}}$ versus $t^{1 / 2}$ for the adsorption of $\mathrm{Cr}(\mathrm{VI})$ fitting as an intraparticle diffusion model are provided in Figure 17. From this figure, it is revealed that plural processes influence the adsorption process for the adsorption of $\mathrm{Cr}(\mathrm{VI})$ by SDS-chitosan beads. In the pseudo-first-kinetic model, the adsorption rate was very high. This may be attributed to the film diffusion of $\mathrm{Cr}(\mathrm{VI})$ through the hydrodynamic layer to the surface of SDS-chitosan beads and the diffusion of $\mathrm{Cr}(\mathrm{VI})$ through the boundary layer to the external surface of the adsorbent. As the sorption on the external surface reaches saturation, $\mathrm{Cr}(\mathrm{VI})$ can enter into the pores of the SDS-chitosan beads and be adsorbed on the internal surface of the mesopores. It is considered that the intraparticle diffusion starts to fall down and reaches an equilibrium stage with the lowering of the $\mathrm{Cr}(\mathrm{VI})$ concentration in solution $[61,71]$.

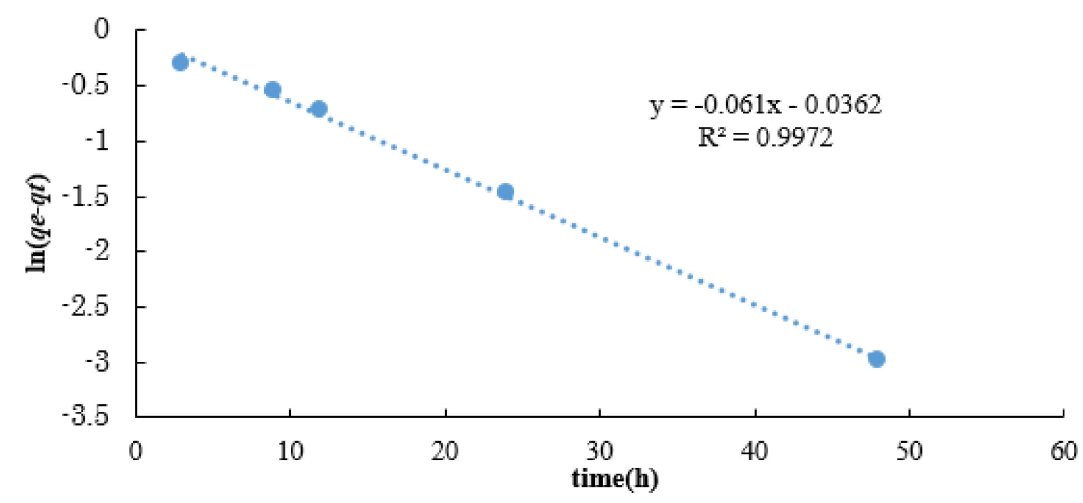

Figure 15. Pseudo-first-order linear kinetic model of $\mathrm{Cr}(\mathrm{VI})$ adsorption on the SDS-chitosan beads.

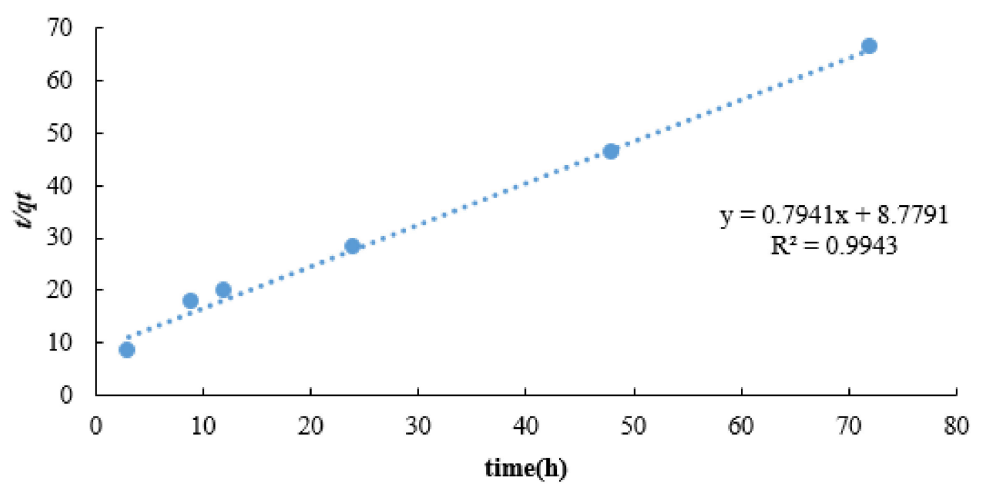

Figure 16. Pseudo-second-order linear kinetic model of $\mathrm{Cr}(\mathrm{VI})$ adsorption on the SDS-chitosan beads.

Table 5. Kinetic parameters of $\mathrm{Cr}(\mathrm{VI})$ adsorption onto the SDS-chitosan beads.

\begin{tabular}{|c|c|c|c|c|c|c|c|}
\hline \multirow{2}{*}{ Adsorbent } & \multirow{2}{*}{$\begin{array}{c}q_{e} \\
(P-m g / g)\end{array}$} & \multicolumn{3}{|c|}{ Pseudo-First-Order Model } & \multicolumn{3}{|c|}{ Pseudo-Second-Order Model } \\
\hline & & $q_{e}(P-m g / g)$ & $k_{1}\left(\min ^{-1}\right)$ & $R^{2}$ & $q_{e}(P-m g / g)$ & $k^{2}\left(g / m g \cdot m^{-1}\right)$ & $R^{2}$ \\
\hline SDS40 & 1.09 & 1.04 & 0.0610 & 0.997 & 1.26 & 0.0718 & 0.994 \\
\hline
\end{tabular}




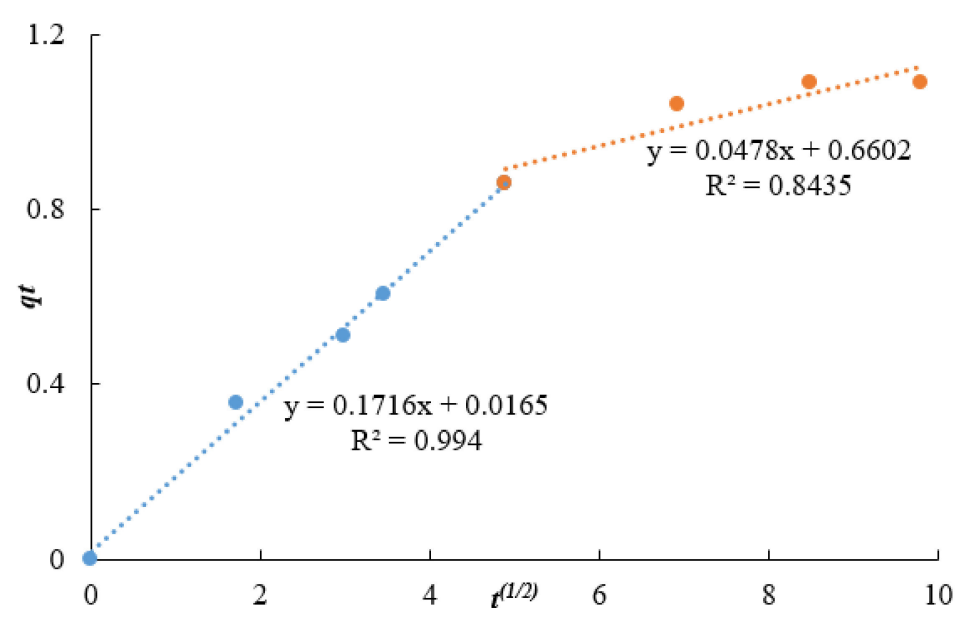

Figure 17. Intraparticle plot for the adsorption of $\mathrm{Cr}(\mathrm{VI})$ by the SDS-chitosan beads.

\subsection{Thermodynamic Study}

The adsorption experiments of $\mathrm{Cr}(\mathrm{VI})$ were carried out from 288 to $318 \mathrm{~K}$ for the thermodynamic investigation. Thermodynamic parameters such as Gibb's free energy change $(\Delta G)$, enthalpy change $(\Delta H)$, and entropy change $(\Delta S)$ were calculated from the adsorption isotherms at different temperatures. All of the thermodynamic parameters for the adsorption of $\mathrm{Cr}(\mathrm{VI})$ on SDS-chitosan beads are tabulated in Table 6, and the adsorption capacity of $\mathrm{Cr}(\mathrm{VI})$ depending on the temperature is shown in Figure 18. The negative values of $\Delta G$ suggest the preferred occurrence of spontaneous adsorption over the tested temperatures (288 to $318 \mathrm{~K}$ ). As shown in Figure 18, the adsorption capability of $\mathrm{Cr}(\mathrm{VI})$ on SDS-chitosan beads increased with an increase in temperature. In addition, the minus value of $\Delta G$ increased with the increase in temperature. This indicates that the adsorption of SDS-chitosan beads on $\mathrm{Cr}(\mathrm{VI})$ is more favorable at a higher temperature. Besides, the enthalpy $\Delta H$ of SDS-chitosan beads $(\Delta \mathrm{H}>0)$ denoted the endothermic adsorption reaction, with the probable better adsorption results at a high temperature. It is known that the value of $\Delta G$ is between 0 and $-20 \mathrm{~kJ} / \mathrm{mol}$ for physisorption, and that it is between -80 and $-400 \mathrm{~kJ} / \mathrm{mol}$ for chemisorption [72]. In certain conditions, the physisorption and chemisorption can be classified by the magnitude of $\Delta H$ and $\Delta G$. Bonding strengths of $<84 \mathrm{~kJ} / \mathrm{mol}$ are typically considered as those of physisorption interaction [73]. Then, it is suggested that the adsorption of $\mathrm{Cr}(\mathrm{VI})$ on SDS-chitosan beads can be mainly dominated by physisorption judging from the values of $\Delta H$ and $\Delta \mathrm{G}$.

Table 6. Thermodynamic parameters for the adsorption of $\mathrm{Cr}(\mathrm{VI})$ on SDS-modified chitosan beads.

\begin{tabular}{cccc}
\hline $\mathbf{T}(\mathbf{K})$ & $\Delta \mathbf{H}(\mathbf{k J} / \mathbf{m o l})$ & $\Delta \mathbf{S}(\mathrm{J} / \mathbf{m o l})$ & $\Delta \mathbf{G}(\mathbf{k J} / \mathbf{m o l})$ \\
\hline 288 & 80.70 & 288.18 & -2.34 \\
298 & - & - & -5.22 \\
308 & - & - & -8.10 \\
318 & - & - & -10.98 \\
\hline
\end{tabular}




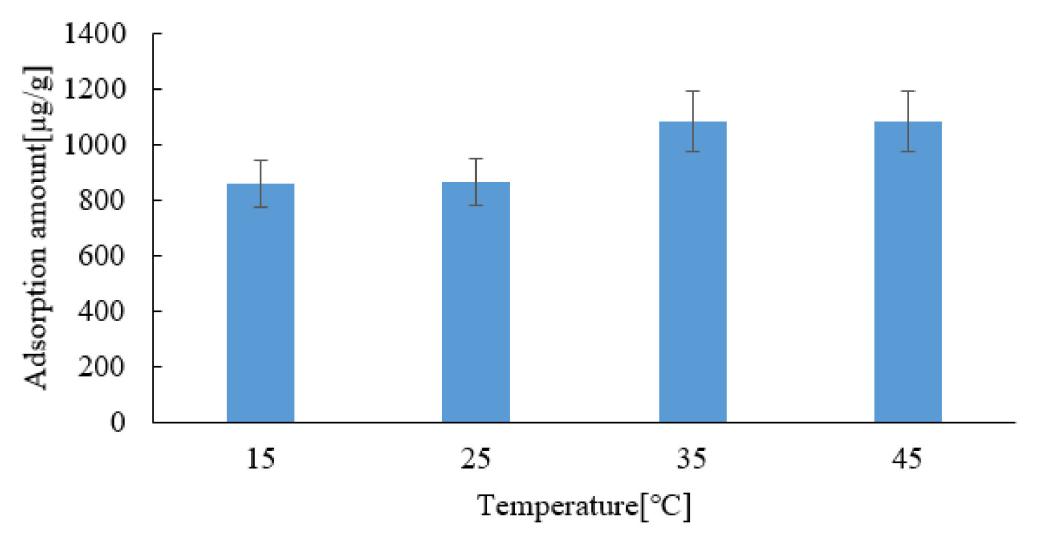

Figure 18. Effect of temperature on the adsorption of $\mathrm{Cr}(\mathrm{VI})$ on the SDS-modified chitosan beads.

\subsection{Desorption Study}

In terms of economically viable applications, the adsorbed material is supposed to be recovered and reused. Based on the procedure of 2.8, preliminary desorption experiments were conducted by using $0.1 \mathrm{~mol} / \mathrm{L} \mathrm{NaOH}$ or pure water, and the results are presented in Figure 19. From this figure, the desorption efficiency of $\mathrm{Cr}(\mathrm{VI})$ was found to be $50 \%$ by using $0.1 \mathrm{~mol} / \mathrm{L} \mathrm{NaOH}$. On the other hand, the desorption was considerably lower with $\mathrm{H}_{2} \mathrm{O}$ than $\mathrm{NaOH}$. It is suggested that $\mathrm{NaOH}$ can be a desorption agent for $\mathrm{Cr}(\mathrm{VI})$, although further investigation is needed for the effective recovery and recycling of $\mathrm{Cr}(\mathrm{VI})$.

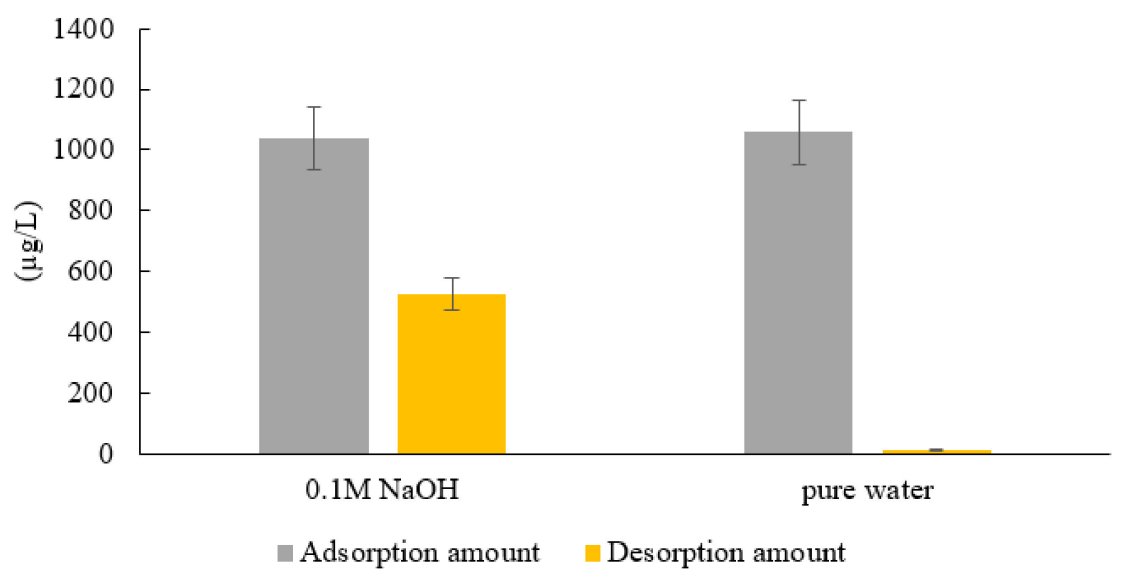

Figure 19. Desorption efficiency of $\mathrm{Cr}(\mathrm{VI})$ using $\mathrm{NaOH}$ or pure water.

\subsection{Comparison with Other Adsorbents}

The maximum adsorption capacity and partition coefficient (PC) of $\mathrm{Cr}(\mathrm{VI})$ on SDS-chitosan beads were compared with those of different adsorbents reported in the literature. The comparison is summarized in Table 7. It is noteworthy that the PC values of SDS-chitosan beads used in this work are remarkably high, although the adsorption capacity is not so high compared to other adsorbents. As denoted in 3.1.6., the maximum adsorption capacity can be sensitively influenced by the initial concentration of objective targets. We regarded that the concept of PC was also important when comparing the adsorption affinity of different adsorbents. 
Table 7. The comparison of adsorption properties of several adsorbents.

\begin{tabular}{|c|c|c|c|c|}
\hline Adsorbents & $\begin{array}{c}\text { Final } \\
\text { Concentration } \\
\left(\mathrm{mg} \cdot \mathrm{L}^{-1}\right)\end{array}$ & $\begin{array}{c}\text { Adsorption } \\
\text { Capacity }\left(\mathrm{mg} \cdot \mathrm{g}^{-1}\right)\end{array}$ & $\begin{array}{c}\text { Partition } \\
\text { Coefficient } \\
\left(\mathrm{mg} \cdot \mathrm{g}^{-1} \cdot \mathrm{mM}^{-1}\right)\end{array}$ & Reference \\
\hline Magnetic Chitosan & 30.6 & 69.4 & 2.3 & [14] \\
\hline $\begin{array}{c}\text { Carboxymethyl } \\
\text { Chitosan-Silicon Dioxide }\end{array}$ & 39.9 & 80.7 & 2.1 & [30] \\
\hline Chitosan-g-poly/silica & $44.3 \times 10^{-3}$ & $55.7 \times 10^{-3}$ & 1.3 & [74] \\
\hline $\begin{array}{l}\text { Crosslinked chitosan } \\
\text { bentonite composite }\end{array}$ & 210.87 & 89.1 & 0.42 & [75] \\
\hline Graphene oxide/chitosan & 13.8 & 86.2 & 6.2 & [76] \\
\hline $\begin{array}{l}\text { Ethylenediamine-magnetic } \\
\text { chitosan }\end{array}$ & 148.2 & 51.8 & 0.35 & [77] \\
\hline SDS-chitosan & 0.34 & 3.23 & 9.5 & This study \\
\hline
\end{tabular}

\section{Conclusions}

In this study, chitosan was chemically modified by sodium dodecyl sulfate (SDS) to enhance its adsorption capacity for the removal of $\mathrm{Cr}(\mathrm{VI})$. The SDS-chitosan beads were characterized by SEM-EDS, FT-IR, and XPS. The effect of several operating parameters, such as the loading amounts of SDS, solution $\mathrm{pH}$, contact time, adsorbent dose, temperature, and initial $\mathrm{Cr}(\mathrm{VI})$ concentration, on the adsorption performance was examined in a batch system. The experimental data were found to be fit best using a Langmuir isotherm and pseudo-first-order kinetic models. The performance of the adsorption process was favorable at $\mathrm{pH} 4-5$ and higher temperatures. The results showed that the maximum adsorption capacity and partition coefficient $(\mathrm{PC})$ of $\mathrm{Cr}(\mathrm{VI})$ on SDS modified chitosan beads were $3.23 \mathrm{mg} \cdot \mathrm{g}^{-1}$ and $9.5 \mathrm{mg} \cdot \mathrm{g}^{-1} \cdot \mathrm{mM}^{-1}$, respectively. In conclusion, the SDS-chitosan beads synthesized in this work can be effectively utilized for removing $\mathrm{Cr}(\mathrm{VI})$ ions.

Author Contributions: Experiment and writing, X.D.; experiment and data evaluation, C.K.; measurements of instrument, H.Z.; measurements of instrument and data evaluation, N.M.; supervision and writing, N.K. All authors have read and agreed to the published version of the manuscript.

Funding: The present study was partially supported by The Uchida Energy Science Promotion Foundation. This research was also supported by a fund for the promotion of Niigata University KAAB Projects from the Ministry of Education, Culture, Sports, Science and Technology, Japan.

Acknowledgments: The authors are grateful to Haruo Morohashi of the Industrial Research Institute of Niigata Prefecture for the measurement of XPS and useful advice. The authors also thank Ohizumi, M. of the Office for Environment and Safety, and Teraguchi, M., Nomoto, T. and Tanaka, T. of the Facility of Engineering in Niigata University for permitting the use of ICP-MS, FT-IR, and SEM-EDS.

Conflicts of Interest: The authors declare no conflicts of interest.

\section{References}

1. Madala, S.; Nadavala, S.K.; Vudagandla, S.; Boddu, V.M.; Abburi, K. Equilibrium, kinetics and thermodynamics of cadmium (II) biosorption on to composite chitosan biosorbent. Arab. J. Chem. 2017, 10, 1883-1893. [CrossRef]

2. Han, S.L.; Zang, Y.A.; Gao, Y.; Yue, Q.Y.; Zhang, P.; Kong, W.J.; Jin, B.; Xu, X.; Gao, B.Y. Co-monomer polymer anion exchange resin for removing $\mathrm{Cr}(\mathrm{VI})$ contaminants: Adsorption kinetics, mechanism and performance. Sci. Total Environ. 2020, 709, 1-10. [CrossRef] [PubMed]

3. Pietrelli, L.; Francolini, I.; Piozzi, A.; Sighicelli, M.; Silvestro, I.; Vocciante, M. Chromium (III) Removal from Wastewater by Chitosan Flakes. Appl. Sci. 2020, 10, 1925. [CrossRef]

4. Pietrelli, L.; Ippolito, N.M.; Reverberi, A.P.; Vocciante, M. Heavy Metals Removal and Recovery from Hazardous Leather Sludge. Chem. Eng. Trans. 2019, 76, 1327-1332.

5. Rajapaksha, A.U.; Alam, M.S.; Chen, N.; Alessi, D.S.; Igalavithana, A.D.; Tsang, D.C.W.; Ok, Y.S. Removal of hexavalent chromium in aqueous solutions using biochar: Chemical and spectroscopic investigations. Sci. Total Environ. 2018, 625, 1567-1573. [CrossRef] 
6. Shi, S.; Yang, J.; Liang, S.; Li, M.; Gan, Q.; Xiao, K.; Hu, J.P. Enhanced Cr (VI) removal from acidic solutions using biochar modified by $\mathrm{Fe}_{3} \mathrm{O}_{4} @ \mathrm{SiO}_{2}-\mathrm{NH}_{2}$ particles. Sci. Total Environ. 2018, 628, 499-508. [CrossRef] [PubMed]

7. Wang, Y.; Zhang, N.; Chen, D.; Ma, D.; Liu, G.; Zou, X.; Chen, Y.; Shu, R.; Song, Q.; Lv, W. Facile synthesis of acid- modified UiO-66 to enhance the removal of $\mathrm{Cr}$ (VI) from aqueous solutions. Sci. Total Environ. 2019, 682, 118-127. [CrossRef] [PubMed]

8. Fendorf, S.E. Surface reactions of chromium in soils and waters. Geoderma 1995, 67, 55-71. [CrossRef]

9. Yamada, K.; Ishiguro, Y.; Kimura, Y.; Asamoto, H.; Minamisawa, H. Two-step grafting of 2-hydroxyethyl methacrylate (HEMA) and 2-(dimethylamino)ethyl methacrylate (DMAEMA) onto a polyethylene plate for enhancement of Cr (VI) ion adsorption. Environ. Technol. 2019, 40, 855-869. [CrossRef]

10. Fu, F.; Wang, Q. Removal of Heavy Metal Ions from Wastewater: A Review. J. Environ. Manag. 2011, 92, 407-418. [CrossRef]

11. Rahmati, M.M.; Rabbani, P.; Abdolali, A.; Keshtkar, A.R. Kinetics and Equilibrium Studies on Biosorption of Cadmium, Lead and Nickel Ions from Aqueous Solutions by Intact and Chemically Modified Brown Algae. J. HazardA. Mater. 2011, 185, 401-407. [CrossRef] [PubMed]

12. Chour, Z.; Laubie, B.; Morel, J.L.; Tang, Y.; Qiu, R.L.; Simonnot, M.O.; Muhr, L. Recovery of rare earth elements from Dicranopteris dichotoma by an enhanced ion exchange leaching process. Chem. Eng. Process. 2018, 130, 208-213. [CrossRef]

13. Yang, M.J.; Liang, X.L.; Ma, L.Y.; Huang, J.; He, H.P.; Zhu, J.X. Adsorption of REEs on kaolinite and halloysite: A link to the REE distribution on clays in the weathering crust of granite. Chem. Geol. 2019, 525, 210-217. [CrossRef]

14. Huang, G.; Zhang, H.; Shi, J.X.; Langrish, T.S.G. Adsorption of Chromium (VI) from Aqueous Solutions Using Cross-Linked Magnetic Chitosan Beads. J. Ind. Eng. Chem. Res. 2009, 48, 2646-2651. [CrossRef]

15. Ngah, W.S.; Ghani, S.A.; Kamari, A. Adsorption Behaviour of Fe (II) and Fe (III) Ions in Aqueous Solution on Chitosan and Cross-linked Chitosan Beads. Bioresour. Technol. 2005, 96, 443-450. [CrossRef] [PubMed]

16. Wang, G.; Liu, J.; Wang, X.; Xie, Z.Y.; Deng, N. Adsorption of Uranium (VI) from Aqueous Solution onto Cross-Linked Chitosan. J. Hazard. Mater. 2009, 168, 1053-1058. [CrossRef]

17. Inoue, K.; Fingerman, M.; Nagabhushanam, R.; Thompson, M. Application of chitosan in separation and purification of metals. Recent Adv. Mar. Biotechnol. Environ. Mar. Biotechnol. 1998, 2, 63-97.

18. Guibal, E.; Larkin, A.; Vincent, T.; Tobin, J.M. Chitosan sorbents for platinum sorption from dilute solutions. Ind. Eng. Chem. Res. 1999, 38, 4011-4022. [CrossRef]

19. Guzman, J.; Saucedo, I.; Revilla, J.; Navarro, R.; Guibal, E. Vanadium interactions with chitosan: Influence of polymer protonation and metal speciation. Langmuir 2002, 18, 1567-1573. [CrossRef]

20. Ng, J.C.Y.; Cheung, W.H.; McKay, G. Equilibrium Studies of the Sorption of Cu (II) Ions onto Chitosan. J. Colloid Interface Sci. 2002, 255, 64-74. [CrossRef]

21. Arrascue, M.L.; Garcia, H.M.; Horna, O.; Guibal, E. Gold sorption on chitosan derivatives. Hydrometallurgy 2003, 71, 191-200. [CrossRef]

22. Gerente, C.; Lee, V.C.; Cloirec, P.L.; McKay, G. Application of Chitosan for the Removal of Metals from Wastewaters by Adsorption-Mechanisms and Models Review. Crit. Rev. Environ. Sci. Technol. 2007, 37, 41-127. [CrossRef]

23. Repoa, E.; Warchoł, J.K.; Bhatnagar, A.; Sillanpää, M. Heavy metals adsorption by novel EDTA-modified chitosan-silica hybrid materials. J. Colloid Interface Sci. 2011, 358, 261-267. [CrossRef] [PubMed]

24. Varma, A.J.; Deshpande, S.V.; Kennedy, J.F. Metal complexation by chitosan and its derivatives: A review. Carbohydr. Polym. 2004, 55, 77-93. [CrossRef]

25. Dutta, P.K.; Dutta, J.; Chattopadhyaya, M.C.; Tripathi, V.S. Chitin and chitosan: Novel biomaterials waiting for future developments. J. Polym. Mater. 2004, 21, 321-333.

26. Kyzas, G.Z.; Bikiaris, D.N. Recent modifications of chitosan for adsorption applications: A critical and systematic review. Mar. Drugs 2015, 13, 312-337. [CrossRef]

27. Bois, L.; Bonhommé, A.; Ribes, A.; Pais, B.; Raffin, G.; Tessier, F. Functionalized silica for heavy metal ions adsorption. Colloids Surf. A Physicochem. Eng. Asp. 2003, 221, 221-230. [CrossRef]

28. Jal, P.K.; Patel, S.; Mishra, B.K. Chemical modification of silica surface by immobilization of functional groups for extractive concentration of metal ions. Talanta 2004, 62, 1005-1028. [CrossRef] 
29. Gandhi, M.R.; Meenakshi, S. Preparation and characterization of silica gel/chitosan composite for the removal of $\mathrm{Cu}$ (II) and $\mathrm{Pb}$ (II). Int. J. Biol. Macromol. 2012, 50, 650-657. [CrossRef]

30. Deng, Y.; Kano, N.; Imaizumi, H. Adsorption of Cr (VI) onto Hybrid Membrane of Carboxymethyl Chitosan and Silicon Dioxide. J. Chem. 2017, 2017, 1-8. [CrossRef]

31. Mishima, K.; Du, X.; Sekiguchi, S.; Kano, N. Experimental and theoretical studies on the adsorption and desorption mechanisms of chromate ions on cross-linked chitosan. J. Funct. Biomater. 2017, 8, 51. [CrossRef] [PubMed]

32. Das, D.; Pal, A. Adsolubilization phenomenon perceived in chitosan beads leading to a fast and enhanced malachite green removal. J. Chem. Eng. 2016, 290, 371-380. [CrossRef]

33. Bolto, B.; Gregory, J. Organic polyelectrolytes in water treatment. Water Res. 2007, 41, 2301-2324. [CrossRef] [PubMed]

34. Gregory, J.; Barany, S. Adsorption and flocculation by polymers and polymer mixtures. Adv. Colloid Interface Sci. 2011, 169, 1-12. [CrossRef]

35. Nasser, M.S.; James, A.E. The effect of polyacrylamide charge density and molecular weight on the flocculation and sedimentation behaviour of kaolinite suspensions. Sep. Purif. Technol. 2006, 52, 241-252. [CrossRef]

36. Mathieu, L.; Benoit, B. Understanding the roles and characterizing the intrinsic properties of synthetic vs. natural polymers to improve clarification through interparticle Bridging: A review. Sep. Purif. Technol. 2020, 231, 115893-115917.

37. Pal, P.; Pal, A. Surfactant-modified chitosan beads for cadmium ion adsorption. Int. J. Biol. Macromol. 2017, 104, 1548-1555. [CrossRef]

38. Pal, P.; Pal, A. Treatment of real wastewater: Kinetic and thermodynamic aspects of cadmium adsorption onto surfactant-modified chitosan beads. Int. J. Biol. Macromol. 2019, 131, 1092-1100. [CrossRef]

39. Ayawei, N.; Ekubo, A.T.; Wankasi, D.; Dikio, E.D. Synthesis and Application of Layered Double Hydroxide for the removal of Copper in Wastewater. Int. J. Chem. 2015, 7, 122-132.

40. Ayawei, N.; Ekubo, A.T.; Wankasi, D.; Dikio, E.D. Adsorption Dynamics of Copper Adsorption by Zn/Al-CO 3 . IJACSA 2015, 3, 57-64.

41. Nešić, A.R.; Veličković, S.J.; Antonović, D.G. Modification of chitosan by zeolite A and adsorption of Bezactive Orange 16 from aqueous solution. Compos. Part B 2013, 53, 145-151. [CrossRef]

42. Dolatyari, L.; Yaftian, M.R.; Rostamnia, S. Adsorption characteristics of Eu (III) and Th (IV) ions onto modified mesoporous silica SBA-15 materials. J. Taiwan Inst. Chem. Eng. 2016, 60, 174-184. [CrossRef]

43. Khan, A.A.; Singh, R.P. Adsorption thermodynamics of carbofuran on Sn (IV) arsenosilicate in $\mathrm{H}^{+}, \mathrm{Na}^{+}$and $\mathrm{Ca}^{2+}$ forms. Colloid Surf. 1987, 24, 33-42. [CrossRef]

44. Farouq, R.; Yousef, N.S. Equilibrium and Kinetics Studies of adsorption of Copper (II) Ions on Natural Biosorbent. Int. J. Chem. Eng. Appl. 2015, 6, 319-324. [CrossRef]

45. Ayawei, N.; Ekubo, A.T.; Wankasi, D.; Dikio, E.D. Adsorption of Congo Red by Ni/Al-CO3: Equilibrium, Thermodynamic and Kinetic Studies. Orient. J. Chem. 2015, 31, 1307-1318. [CrossRef]

46. Guibal, E.; Roussy, J. Coagulation and flocculation of dye-containing solutions using a biopolymer (Chitosan). React. Funct. Polym. 2007, 67, 33-42. [CrossRef]

47. Bolto, B. Soluble polymers in water purification. Prog. Polym. Sci. 1995, 20, 987-1041. [CrossRef]

48. Wu, Y.; Luo, H.J.; Wang, H.; Wang, C.; Zhang, J.; Zhang, Z.L. Adsorption of Hexavalent Chromium from Aqueous Solutions by Graphene Modified with Cetyltrimethylammonium Bromide. J. Colloid Interface Sci. 2013, 394, 183-191. [CrossRef]

49. Gupta, V.K.; Nayak, A. Cadmium removal and recovery from aqueous solutions by novel adsorbents prepared from orange peel and $\mathrm{Fe}_{2} \mathrm{O}_{3}$ nanoparticles. J. Chem. Eng. 2012, 180, 81-90. [CrossRef]

50. Khobragade, M.U.; Pal, A. Adsorptive removal of Mn (II) from water and wastewater by surfactant-modified alumina. Desalin. Water Treat. 2016, 57, 2775-2786. [CrossRef]

51. Li, M.; Zhang, Z.; Li, R.; Wang, J.J.; Ali, A. Removal of Pb (II) and Cd (II) ions from aqueous solution by thiosemicarbazide modified chitosan. Int. J. Biol. Macromol. 2016, 86, 876-884. [CrossRef] [PubMed]

52. Vikrant, K.; Kim, K.H. Nanomaterials for the adsorptive treatment of $\mathrm{Hg}$ (II) ions from water. Chem. Eng. J. 2019, 358, 264-282. [CrossRef]

53. Na, C.J.; Yoo, M.J.; Tsang, D.C.W.; Kim, H.W.; Kim, K.H. High-performance materials for effective sorptive removal of formaldehyde in air. J. Hazard. Mater. 2019, 366, 452-465. [CrossRef] [PubMed] 
54. Zhang, S.; Kano, N.; Mishima, K.; Okawa, H. Adsorption and Desorption Mechanisms of Rare Earth Elements (REEs) by Layered Double Hydroxide (LDH) Modified with Chelating Agents. Appl. Sci. 2019, 9, 4805. [CrossRef]

55. Motawie, A.M.; Mahmoud, K.F.; El-Sawy, A.A.; Kamal, H.M.; Hefni, H.; Ibrahiem, H.A. Preparation of chitosan from the shrimp shells and its application for pre-concentration of uranium after cross-linking with epichlorohydrin. J. Egypt. J. Pet. 2014, 23, 221-228. [CrossRef]

56. Ngah, W.W.; Endud, C.S.; Mayanar, R. Removal of Copper (II) Ions from Aqueous Solution onto Chitosan and Cross-linked Chitosan Beads. React. Funct. Polym. 2002, 50, 181-190. [CrossRef]

57. Cestari, A.R.; Vieira, E.F.S.; Oliveira, I.A.; Bruns, R.E. The removal of $\mathrm{Cu}$ (II) and Co (II) from aqueous solutions using cross-linked chitosan-evaluation by the Factorial Design Methodology. J. Hazard. Mater. 2007, 143, 8-16. [CrossRef]

58. Zhang, Q.; Wu, Q.; Lin, D.; Yao, S. Effect and mechanism of sodium chloride on the formation of chitosan-cellulose sulfate-tripolyphosphate crosslinked beads. Soft Matter 2013, 9, 10354-10363. [CrossRef]

59. Wang, W.; Lu, H.; Liu, Y.; Leng, J. Sodium dodecyl sulfate/epoxy composite: Water-induced shape memory effect and its mechanism. J. Mater. Chem. A 2014, 2, 5441-5449. [CrossRef]

60. Antony, N.; Sherine, H.B.; Rajendran, S. Inhibition and biocide actions of sodium dodecyl sulfate- $\mathrm{Zn}^{2+}$ system for the corrosion of carbon steel in chloride solution. Port. Electrochim. Acta 2010, 28, 1-14. [CrossRef]

61. Zhao, H.; Liu, X.; Cao, Z.; Zhan, Y.; Shi, X.D.; Yang, Y.; Zhou, J.L.; Xu, J. Adsorption behavior and mechanism of chloramphenicols sulfonamides, and non- antibiotic pharmaceuticals on multi-walled carbon nanotubes. J. Hazard. Mater. 2016, 310, 235-245. [CrossRef] [PubMed]

62. Langmuir, I. The constitution and fundamental properties of solids and liqiuds. Part I. Solids. J. Am. Chem. Soc. 1917, 38, 102-105.

63. Freundlich, H.M.F. Uber die adsorption in lunsungen. J. Phys. Chem. 1985, 57, 387-470.

64. Chakraborty, P.; Nagarajan, R. Efficient adsorption of malachite green and congo red dyes by the surfactant (DS) intercalated layered hydroxide containing $\mathrm{Zn}^{2+}$, and $\mathrm{Y}^{3+}$ ions. Appl. Clay Sci. 2015, 118, 308-315. [CrossRef]

65. Yu, S.; Wang, X.; Chen, Z.; Wang, J.; Wang, S.; Hayat, T.; Wang, X. Layered double hydroxide intercalated with aromatic acid anions for the efficient capture of aniline from aqueous solution. J. Hazard. Mater. 2017, 321, 111-120. [CrossRef]

66. Xiao, L.; Ma, W.; Han, M.; Cheng, Z. The influence of ferric iron in calcined nano-Mg/Al hydrotalcite on adsorption of Cr (VI) from aqueous solution. J. Hazard. Mater. 2011, 186, 690-698. [CrossRef]

67. Lazaridis, N.K.; Asouhidou, D.D. Kinetics of sorptive removal of chromium (VI) from aqueous solutions by calcined Mg-Al-CO 3 hydrotalcite. Water Res. 2003, 37, 2875-2882. [CrossRef]

68. Ho, Y.S.; Mckay, G. The sorption of lead (II) ions on peat. Water Res. 1999, 33, 578-584. [CrossRef]

69. Weber, W.J.; Morris, J.C. Kinetics of adsorption on carbon from solution. Asce Sanit. Eng. Div. J. 1963, 1, 1-2.

70. Yan, L.G.; Yang, K.; Shan, R.R.; Yan, T.; Wei, J.; Yu, S.H.; Yu, H.Q.; Du, B. Kinetic isotherm and thermodynamic investigations of phosphate adsorption onto core-shell $\mathrm{Fe}_{3} \mathrm{O}_{4} @ \mathrm{LDH}$ composites with easy magnetic separation assistance. J. Colloid Interface Sci. 2015, 448, 508-516. [CrossRef]

71. Lv, L.; He, J.; Wei, M.; Evans, D.G.; Duan, X. Uptake of chloride ion from aqueous solution by calcined layered double hydroxides: Equilibrium and kinetic studies. Water Res. 2006, 40, 735-743. [CrossRef] [PubMed]

72. Liu, Q.S.; Zheng, T.; Wang, P.; Jiang, J.P.; Li, N. Adsorption isotherm, kinetic and mechanism studies of some substituted phenols on activated carbon fibers. J. Chem. Eng. 2010, 157, 348-356. [CrossRef]

73. Jaycock, M.J.; Parfitt, G.D. Chemistry of Interfaces; Ellis Horwood: Chichester, UK, 1981; Volume 85. [CrossRef]

74. Nithya, R.; Gomathi, T.; Sudha, P.N.; Venkatesan, J.; Anil, S.; Kim, S.K. Removal of Cr (VI) from aqueous solution using chitosan-g-poly (butyl acrylate)/silica gel nanocomposite. Int. J. Biol. Macromol. 2016, 7, 545-554. [CrossRef] [PubMed]

75. Liu, Q.; Yang, B.; Zhang, L.; Huang, R. Adsorptive removal of Cr (VI) from aqueous solutions by cross-linked chitosan/bentonite composite. Korean J. Chem. Eng. 2015, 32, 1314-1322. [CrossRef] 
76. Zhang, L.; Luo, H.; Liu, P.; Fang, W.; Geng, J. Anovelmodified graphene oxide/chitosan composite used as an adsorbent for $\mathrm{Cr}(\mathrm{VI})$ in aqueous solutions. Int. J. Biol. Macromol. 2016, 87, 586-596. [CrossRef]

77. Hu, X.J.; Wang, J.S.; Liu, Y.G.; Li, X.; Zeng, G.M.; Bao, Z.L.; Zeng, X.X.; Chen, A.W.; Long, F. Adsorption of chromium (VI) by ethylenediamine-modified cross-linked magnetic chitosan resin: Isotherms, kinetics and thermodynamics. J. Hazard. Mater. 2011, 185, 306-314. [CrossRef]

(C) 2020 by the authors. Licensee MDPI, Basel, Switzerland. This article is an open access article distributed under the terms and conditions of the Creative Commons Attribution (CC BY) license (http://creativecommons.org/licenses/by/4.0/). 